\title{
Keratin 8 reduces colonic permeability and maintains gut microbiota homeostasis, protecting against colitis and colitis- associated tumorigenesis
}

\author{
Chao Liuu',2,*, En-Dong Liu'2,*, Yun-Xiao Meng ${ }^{3, *}$, Xiao-Ming Dong ${ }^{4}$, Ya-Lan Bí ${ }^{3}$, Huan- \\ Wen $\mathrm{Wu}^{3}$, Yan-Chao Jin², Ke Zhao', Jian-Jie Li ${ }^{5}$, Miao Yu ${ }^{2}$, Yi-Qun Zhan², Hui Chen², \\ Chang-Hui Ge ${ }^{2}$, Xiao-Ming Yang ${ }^{1,2,4}$ and Chang-Yan $\mathbf{L i}^{1,2}$ \\ ${ }^{1}$ An Hui Medical University, Hefei, 230032, China \\ ${ }^{2}$ State Key Laboratory of Proteomics, Beijing Proteome Research Center, Beijing Institute of Radiation Medicine, Beijing, \\ 100850, China \\ ${ }^{3}$ Department of Pathology, Peking Union Medical College Hospital, Chinese Academy of Medical Sciences and Peking Union \\ Medical College, Tsinghua University, Beijing, 100730, China \\ ${ }^{4}$ Tianjin University, School of Chemical Engineering and Technology, Department of Pharmaceutical Engineering, Tianjin, \\ 300072, China \\ ${ }^{5}$ Key Laboratory of Carcinogenesis and Translational Research, Ministry of Education, Department of Thoracic Oncology, \\ Peking University Cancer Hospital Institute, Beijing, 100871, China \\ *These authors contributed equally to this work
}

Correspondence to: Xiao-Ming Yang, email: xiaomingyang@sina.com Chang-Yan Li, email: fmmli@163.com

Keywords: CK8, colitis, colitis-associated colorectal cancer, gut microbiota, TLR4

Received: February 21, 2017 Accepted: May 13, $2017 \quad$ Published: May 27, 2017

Copyright: Liu et al. This is an open-access article distributed under the terms of the Creative Commons Attribution License 3.0 (CC BY 3.0), which permits unrestricted use, distribution, and reproduction in any medium, provided the original author and source are credited.

\section{ABSTRACT}

Keratin 8 (CK8) is the major component of the intermediate filaments of simple or single-layered epithelia. Gene targeting mice model suggest that CK8 is involved in colonic active ion transport, colorectal hyperplasia and inflammation. In the present study, we found that CK8 is downregulated in the colon during DSS-induced colitis and AOM/DSS-induced colitis-associated colorectal cancer (CAC) development. In human patients with colon cancer, CK8 is downregulated. Using CK8 heterozygous knockout mice $\left(\mathrm{CK8}^{+/-}\right)$, we found that $\mathrm{CK8}^{+/-}$mice are highly susceptible to DSS-induced colitis and more prone to AOM/DSS-induced CAC than wild type (WT) mice. The colonic permeability is increased with DSS or AOM/DSS treatment, leading to alteration of gut microbiota in $\mathrm{CK8}^{+/-}$mice with CAC. Metagenomic analysis of fecal microbiota suggests Firmicutes and Proteobacteria are increased in $\mathrm{CK}^{+/-}$mice with $\mathrm{CAC}$, while Bacteroidetes and Verrucomicrobia are decreased. Antibiotic treatment decreases the incidence of colorectal cancer tumorigenesis and TLR4 inhibitor attenuates the susceptibility of $\mathrm{CK}^{+/-}$mice to DSS-induced colitis. These data suggest CK8 protects mice from colitis and colitis-associated colorectal cancer by modulating colonic permeability and gut microbiota composition homeostasis.

\section{INTRODUCTION}

Chronic inflammation of the gut, such as that observed in inflammatory bowel disease (IBD), strongly predicts colitis-associated colorectal cancer (CAC) incidence and progression [1-3]. In their first 30 years with IBD, over a fifth of patients develop CAC, and half of these CAC cases are fatal [4]. Though the pathogenesis of IBD and CAC are not yet fully known, there is a general consensus that inflammatory conditions and the intestinal 
commensal microbiota composition are major contributors to the development of these diseases. Still, there is a great need for research into the regulation of these factors.

In the majority of eukaryotic cell types, intermediate filaments (IFs) are key constituents of the nuclear envelope and cytoskeleton [5]. The keratin subfamily, expressed specifically by epithelial cells, comprises more than 20 proteins (keratins 1-20). Type I proteins (keratins 9-20) pair with type II proteins (keratins 1-8), forming obligate noncovalent heteropolymers [6]. In the exocrine pancreas, liver, gastrointestinal tract and mammary gland, the simple or single-layered epithelia (where carcinomas frequently arise) contain IFs predominantly composed of keratins 8 and $18(\mathrm{CK} 8 / 18)$ [7].

Animal studies have indicated that CK8 is involved in the development of IBD. One report [8] demonstrated that homozygous $\mathrm{CK} 8^{-/-} \mathrm{FVB} / \mathrm{N}$ mice developed colitis, colonic hyperplasia and rectal prolapse. Hyperplasia was evident in histological analyses, while the crypt cells and mucin-producing goblet cells appeared normal; thus, colorectal hyperplasia seemed to be responsible for the bowel inflammation in $\mathrm{CK}^{-/-}$mice [8]. Chronic $\mathrm{T}$ helper type 2 colitis (Th2 colitis) was also reported to occur spontaneously in $\mathrm{CK}^{-/-}$mice [9]. Immunohistochemical and flow cytometric analyses revealed that the infiltration of T-cell receptor beta (TCR $\beta$ )-positive $\mathrm{CD}^{+}{ }^{+} \mathrm{T}$ cells into the lamina propria of the colon, as well as the production of Th2 cytokines (IL-4, IL-5 and IL-13), was elevated in $\mathrm{CK}^{-/-}$mice. However, antibiotics such as imipenem and vancomycin inhibited the inflammation of the $\mathrm{CK}^{-/-}$colon, indicating that bacteria in the lumen may induce colitis when there is a primary epithelial defect in mice [9]. In addition, the active transport of ions (sodium and chloride) in the colons of $\mathrm{CK} 8$-null $\left(\mathrm{CK}^{-/-}\right.$and $\mathrm{CK}^{+/-}$) mice differed from that of $\mathrm{CK} 8^{+/+}$mice [10]. The short circuit current $\left(\mathrm{I}_{\mathrm{SC}}\right)$ was also significantly reduced in CK8-null mice; however, their colon tissues exhibited normal paracellular transport and conductance [10]. This indicated that keratins may regulate ion transport proteins and the transport of electrolytes in colonocytes [10].

A subgroup of IBD patients was recently reported to have missense mutations in CK8 [11]. In a proteomic study of patients with colorectal cancer (CRC), polyps or no pathology, certain isoforms of CK8 were expressed at higher levels in morphologically normal mucosa from polyp and cancer patients than in those from healthy subjects [12]. CK8 expression in CRC was also reported to correlate directly with survival, potentially because of its relationship to the epithelial-mesenchymal transition [13]. All these data suggest that CK8 is involved in barrier protection, colonic active ion transport, colorectal hyperplasia and inflammation. However, the involvement of CK8 in inflammation-associated CRC remains poorly understood.

Embryonic lethality has been reported to occur in about $50 \%$ of homozygous CK8 knockout mice. Our previous study demonstrated that CK8 was completely abolished in $\mathrm{CK} 8^{-/-}$mice, while $\mathrm{CK} 8^{+/-}$mice had about half the $\mathrm{CK} 8$ level of $\mathrm{CK}^{+/+}$mice in all examined tissues [14]. Furthermore, $\mathrm{CK}^{+/-}$mice were phenotypically similar to wild-type (WT) controls, with only slight crypt proliferation and partial ion transport dysfunction [10]. Only $3 \%$ of heterozygous mice exhibited anorectal prolapse. These data suggest that $\mathrm{CK} 8^{+/-}$mice are a usable model mimicking CK8 knockout mice.

In the present study, we have examined CK8 expression in experimental colitis and CAC models and in clinical patients with colon cancer. Using $\mathrm{CK}^{+/-}$mice, we have investigated the effects of CK8 on the gut microbiota composition and intestinal permeability during dextran sodium sulfate (DSS)-induced colitis and azoxymethane (AOM)/DSS-induced CAC. Finally, we have assessed the influence of antibiotics and a toll-like receptor 4 (TLR4) inhibitor on CRC tumorigenesis and DSS-induced colitis, respectively, in $\mathrm{CK}^{+/-}$mice.

\section{RESULTS}

\section{CK8 is downregulated in colitis and CAC}

Colorectal cancer risk is elevated in ulcerative colitis patients $[15,16]$. CK8 is the major component of the IFs in the gut epithelium, and is downregulated in CRC [7]. The absence of CK8 in mice stimulates the development of colonic hyperplasia and colitis[8]. These data suggest that CK8 might be important for preventing CAC.

We first detected the expression of colonic CK8 during DSS-induced acute colitis. Age- and sex-matched $\mathrm{CK}^{+/+}$ and $\mathrm{CK}^{+-}$mice were treated with $5 \%$ DSS for 5 days, and colonic CK8 expression was examined. As shown in Figure 1A, colonic CK8 expression was significantly reduced in the $\mathrm{CK}^{+/+}$mouse following colonic injury with DSS, and was almost undetectable in $\mathrm{CK}^{+/-}$mice.

We then treated mice with AOM/DSS, a wellestablished method of inducing CAC [9]. Consistent with previous reports $[17,18]$, when WT mice were intraperitoneally injected with a single dose of AOM (a carcinogen) and given three cycles of $2 \%$ DSS in their drinking water, they developed multiple middle- to distalcolon tumors (data not shown). We next assessed the colonic expression of CK8 during CAC. As shown in Figure 1B, CK8 expression was significantly reduced in both $\mathrm{CK}^{+/+}$and $\mathrm{CK}^{+/-}$mice after AOM/DSS treatment; however, by the end of the third cycle, the expression of CK8 was almost undetectable in $\mathrm{CK} 8^{+-}$mice.

Given the above observations, we predicted that CK8 expression might decrease during the development of colonic inflammation and colon cancers. Thus, we performed immunohistochemistry to determine the levels of CK8 in normal and neoplastic human colon specimens $(n=102)$ with a specific antibody against CK8. The specificity of the CK8 antibody is shown in Supplementary Figure 1. The results demonstrated that 
the surface epithelial cells and crypt cells of the normal colonic mucosa expressed high levels of CK8. On the other hand, in colonic adenocarcinoma specimens, CK8 expression was dramatically reduced (Figure 1C). We also assessed CK8 protein levels in specimens from four colon cancer patients. As expected, CK8 levels were significantly lower in cancer tissues than in para-cancer tissues (Figure 1D).

Taken together, these results indicate that CK8 is downregulated in colorectal tumors and may be important for preventing $\mathrm{CAC}$ tumorigenesis.

A

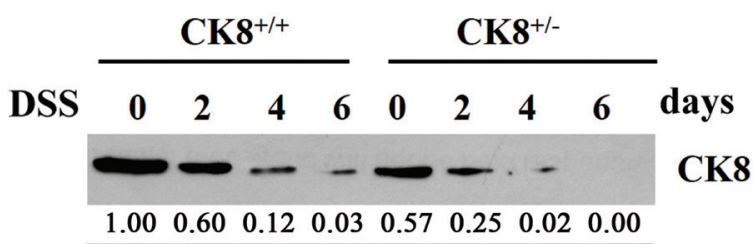

GAPDH

C

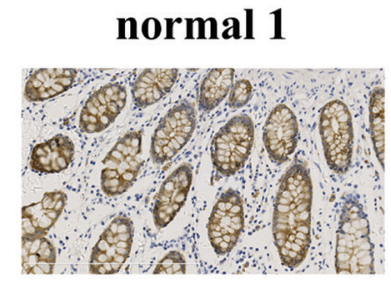

patient 1

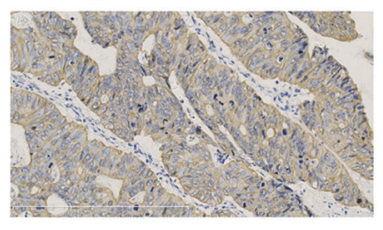

patient 2

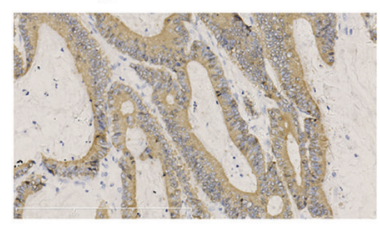

D

patient 1 patient 2 patient 3 patient 4

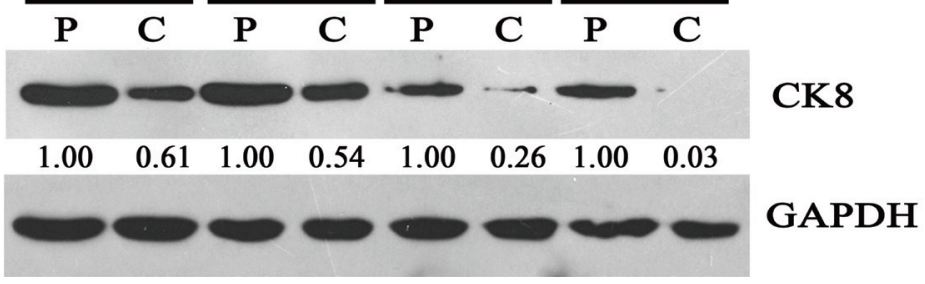

\section{Knockdown of CK8 promotes susceptibility to AOM/DSS-induced CAC}

We further examined the vulnerability of $\mathrm{CK} 8^{+/+}$and $\mathrm{CK}^{+/-}$mice to AOM/DSS-induced CAC tumorigenesis, using a previously reported method [19]. During AOM and DSS treatment, $\mathrm{CK}^{+/-}$mice exhibited greater mortality than WT mice (Figure 2A), and by day 95, about $40 \%$ of the $\mathrm{CK}^{+/-}$mice had died. $\mathrm{CK}^{+/-}$mice also exhibited accelerated weight loss during the DSS treatment cycles (Figure 2B).

B
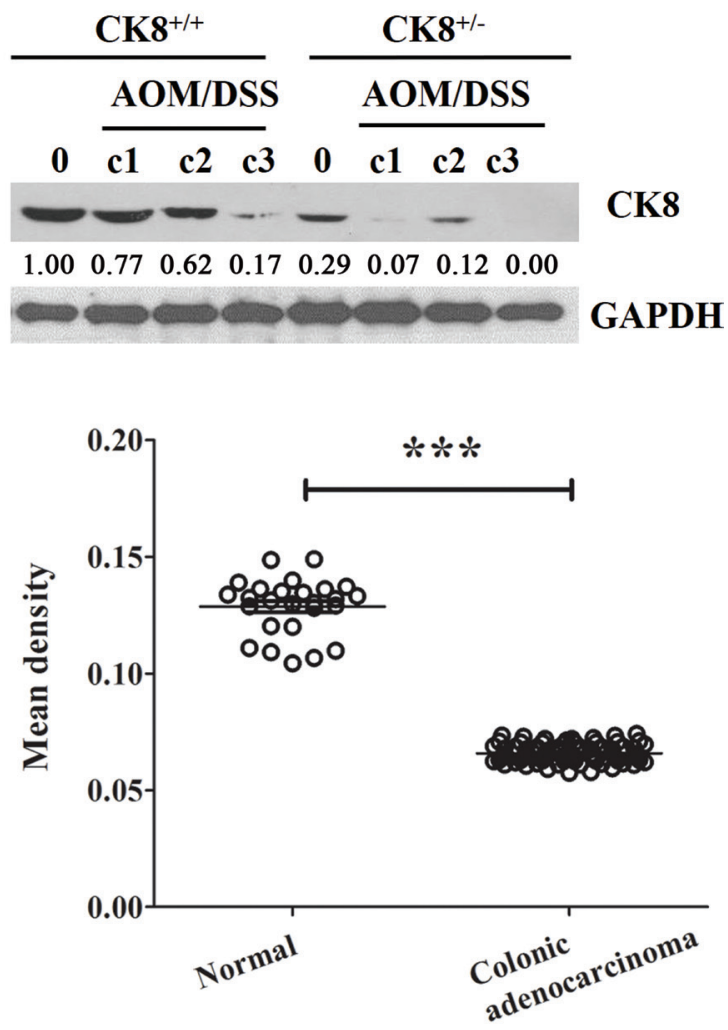

Figure 1: CK8 is down regulated in colitis and colitis-associated colorectal cancer. (A) $\mathrm{CK} 8^{+/+}$mice and $\mathrm{CK} 8^{+/-}$mice were fed with $5 \%$ DSS-containing drinking water for 5 consecutive days and followed by regular water for 1 day. The colonic expression of CK8 were investigated using Western blotting analysis. The blots bands were scanned for densitometry analysis with the value obtained from $\mathrm{CK} 8^{+/+}$mice without DSS treatment set as 1 . (B) Colitis- associated colorectal cancer was induced in $\mathrm{CK} 8^{+/+}$mice and $\mathrm{CK} 8^{+/-}$mice with AOM/DSS treatment as Material and Methods described. The colonic expression of CK8 were investigated using Western blotting analysis. The blots bands were scanned for densitometry analysis with the value obtained from $\mathrm{CK} 8^{+/+}$mice without AOM/DSS treatment set as 1. (C) The expression level of CK8 in human specimens of normal $(n=26)$ and neoplastic colon $(n=76)$ using immunohistochemical analysis with a specific antibody to the CK8 protein. The Mean density of CK8 positive cells in each sample was quantified by Image Proplus 6.0. ${ }^{* * *} P<0.001$.(D) The colonic expression of CK8 in four colon cancer patients were investigated using Western blotting analysis(P: para-cancer tissues, C:cancer tissues). The blots bands were scanned for densitometry analysis with the value obtained from colon cancer patients' para-cancer tissues set as 1 . 
While $\mathrm{CK}^{+/+}$and $\mathrm{CK}^{+/-}$mice treated with $\mathrm{AOM}$ and DSS each developed colonic tumors, the tumor incidence was significantly greater in $\mathrm{CK}^{+/-}$mice than in WT mice after the second cycle of DSS treatment (Figure 2C), and the colon length was shortened in the $\mathrm{CK} 8^{+/-}$group (Figure 2D). At the time of harvest after the third DSS cycle, about $90 \%$ of the $\mathrm{CK} 8^{+/-}$mice had developed tumors, whereas only $58 \%$ of the WT mice exhibited macroscopically visible adenoma lesions (Figure 2E). We counted and measured macroscopic tumors over the entire length of the colon and rectum. As displayed in Figure $2 \mathrm{~F}$ and $2 \mathrm{G}, \mathrm{CK}^{+/-}$ mice developed significantly more tumor lesions than WT mice. The colon and rectal tumors of the $\mathrm{CK}^{+/-}$mice were threefold greater in volume than those of the WT mice. While tumors were mostly found in the colorectal and distal portions of the WT colon, tumors were frequently observed along the whole length of the $\mathrm{CK}^{+/-}$colon.

We also counted Ki-67-stained cells, and found a larger number of positive cells in $\mathrm{CK}^{+/-}$tumors than in WT tumors (Figure $2 \mathrm{H}$ ), suggesting that the downregulation of CK8 enhances the proliferation of tumor cells. However, the extent of apoptosis did not differ in tumorous colons from $\mathrm{CK}^{+/-}$and WT mice (Supplementary Figure 2). The mRNA levels of cancer-related genes including $\beta$-catenin, E-cadherin, Mmp2 and Mmp 9 were higher in $\mathrm{CK} 8^{+/-}$mice than in WT mice (Figure 3).

These observations suggest that the downregulation of CK8 increases the vulnerability of mice to CAC tumorigenesis.

\section{CK8 inhibits DSS-induced inflammatory responses}

Previous studies have suggested that inflammatory conditions are key contributors to CAC tumorigenesis. We therefore hypothesized that $\mathrm{CK}^{+/-}$mice may have been more susceptible to CAC induced by AOM/DSS because of an enhanced inflammatory response to DSS treatment. First, we investigated the influence of CK8 downregulation on the severity of colitis induced by DSS. We treated $\mathrm{CK}^{+/+}$and $\mathrm{CK}^{+/-}$mice for 5 days with $5 \%$ DSS, then for 3 days with normal drinking water. While DSS induced weight loss in both $\mathrm{CK}^{+/+}$and $\mathrm{CK}^{+/-}$mice, a greater extent of weight loss was apparent in $\mathrm{CK}^{+/-}$ mice by day 7 (Figure 4A). By the ninth day, around 90\% of the $\mathrm{CK}^{+/-}$mice were hunched over, had lost roughly $30 \%$ of their body weight, and needed to be euthanized. Although we observed malformed stools and colonic edemas during necropsies of both $\mathrm{CK}^{+/+}$and $\mathrm{CK}^{+/-}$ mice, the $\mathrm{CK}^{+/-}$mice had shorter colons, indicating that their colonic injuries were more severe (Figure 4B). When we examined the histology of Swiss-rolled colons stained with $\mathrm{H} \& \mathrm{E}, \mathrm{CK} 8^{+/-}$colons mainly exhibited distal injuries including epithelial ulcers, submucosal edemas and inflammatory infiltrates, indicating that more severe injuries had occurred in the $\mathrm{CK}^{+/-}$mice (Figure 4C).
We further investigated the expression of various inflammatory cytokines and chemokines in WT and $\mathrm{CK}^{+/-}$mice. The levels of Tnf $\alpha$, If $n \gamma, \mathrm{Il}-1 \alpha, \mathrm{Il}-1 \beta, \mathrm{Il}-17$, Ccl4 and $\mathrm{Il}-6$ were elevated in colon tissues from $\mathrm{CK}^{+/-}$ mice (Figure 4D). Additionally, the levels of typical inflammation markers (nitric oxide synthase (NOS) and cyclooxygenase 2 (COX2)) were greater in $\mathrm{CK}^{+/-}$colons than in WT colons after DSS treatment (Figure 4E). Only the colon (especially the distal portion) exhibited this inflammation, while little inflammation was observed in the small intestine (data not shown). These data are consistent with previous reports and suggest that the downregulation of CK8 stimulates inflammation in DSSstimulated acute colitis.

We next evaluated the inflammatory responses of AOM/DSS-treated mice. More severe colitis was detected in $\mathrm{CK}^{+/-}$mice than in WT mice, as evidenced by their greater weight loss (Figure 2B), more severe diarrhea (Figure 5A) and fecal occult blood (Figure 5B) after DSS treatment. Following long-term DSS treatment, $\mathrm{CK}^{+/-}$ mice had significantly shorter colons than WT mice (Figure 2D). We also evaluated the histopathology of the colon in the early phase of tumor induction (15 days following the injection of AOM). As shown in Figure 5C, the extent of inflammation, mucosal edema, tissue damage, and hyperplasia was significantly greater in $\mathrm{CK}^{+/-}$colons than in WT colons. Then, we evaluated the mRNA levels of various cytokines and inflammatory factors in colon tissues from $\mathrm{CK}^{+/-}$and WT mice with tumors. As shown in Figure 5D, proinflammatory cytokines such as Tnfa, iNos, Ifng and Il-17 and the chemokine Ccl4 were significantly upregulated in $\mathrm{CK}^{+/-}$colons compared to WT colons.

All these data suggest that CK8 is important for dampening inflammatory responses during AOM/DSSinduced CAC tumorigenesis.

\section{$\mathrm{CK8}^{+-}$mice exhibit increased colonic permeability during DSS-induced colitis and AOM/DSS-induced colorectal carcinogenesis}

$\mathrm{TNF} \alpha$ has been shown to be critical for the initiation and progression of colitis and CAC carcinogenesis, and blocking TNF $\alpha$ in mice reduced colorectal carcinogenesis with colitis following AOM and DSS treatment [20]. Since $\mathrm{TNF} \alpha$ was upregulated in $\mathrm{CK}^{+/-}$mice after DSS treatment, it was of interest to determine if blocking TNF $\alpha$ would reduce the colorectal carcinogenesis in $\mathrm{CK}^{+/}$mice. We administered a specific TNF $\alpha$ antagonist (etanercept) to $\mathrm{CK}^{+/-}$mice that had been treated with DSS; however, etanercept did not reduce the incidence of tumorigenesis (data not shown), suggesting that TNF $\alpha$ is not essential for AOM/ DSS-induced colorectal carcinogenesis in $\mathrm{CK}^{+/-}$mice.

A previous study suggested that $\mathrm{CK} 8$, together with IL-6, protects the epithelial barrier from direct luminal damage (such as that from DSS) and the accompanying 
A

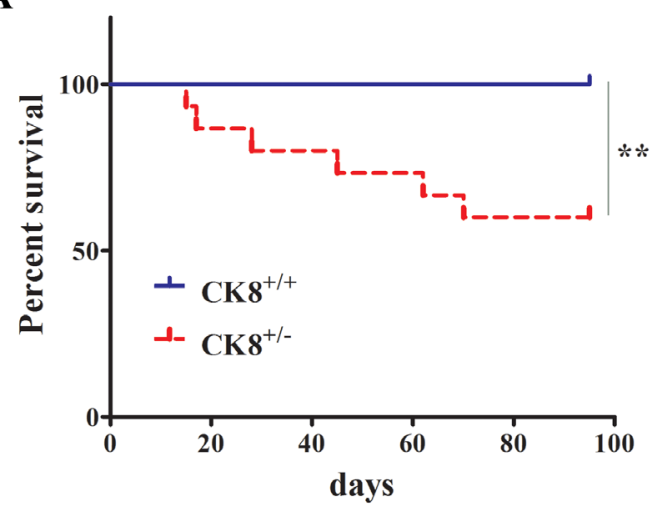

C
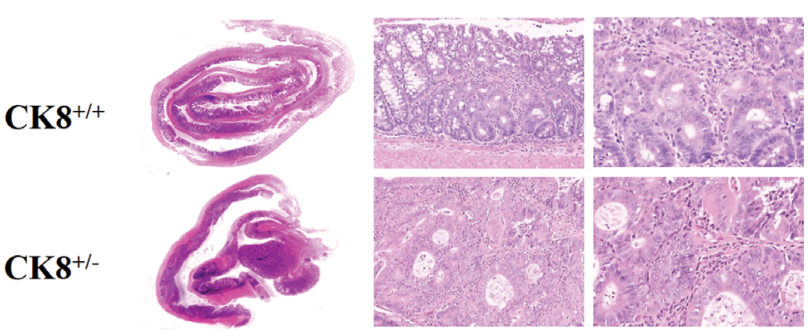

B
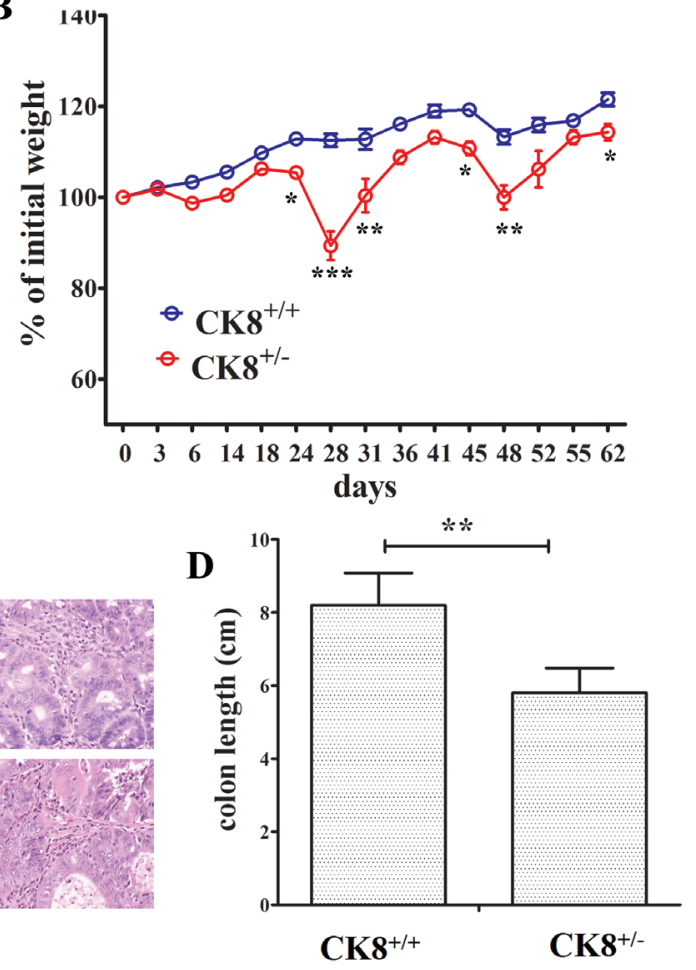

E
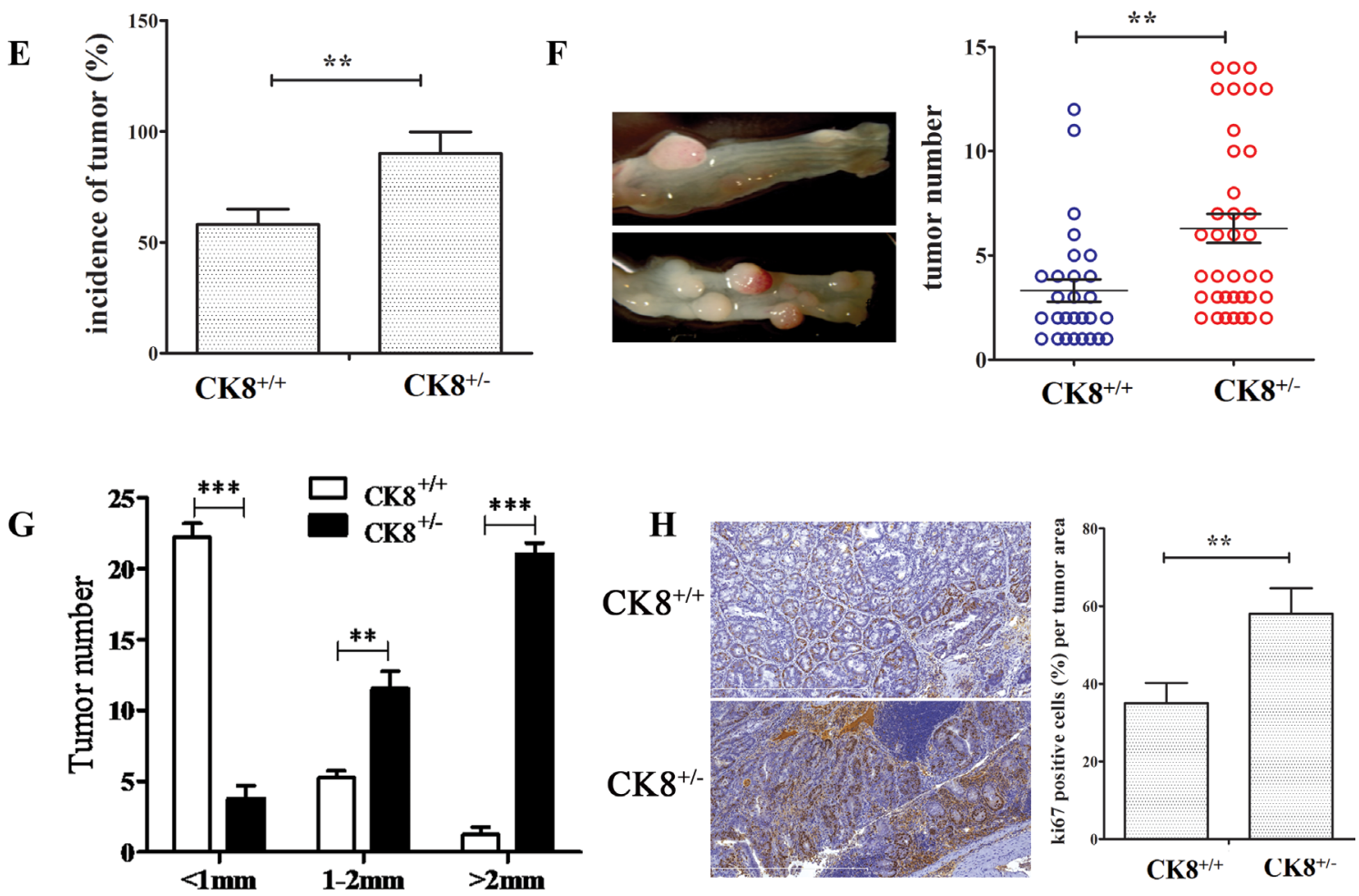

Figure 2: Knockdown of CK8 promotes susceptibility to AOM/DSS-induced colitis-associated colorectal carcinoma. (A) $\mathrm{CK}^{++/}$mice and $\mathrm{CK} 8^{+/-}$mice were treated with AOM/DSS as Material and Methods described. Their survival was monitored until day 96 after treatment with AOM. Survival Differences were evaluated with the Mantel-Cox test. ${ }^{* *} P<0.01$. (B) The mean changes in body weight of the $\mathrm{CK}^{8^{+/+}}$and $\mathrm{CK} 8^{+/-}$mice were measured at the indicated time until day 62 . At the end of 2 nd cycle DSS on day 45 full length of the colon was prepared in a Swiss roll method and subject to H\&E staining $(\mathbf{C})$. The colon length was measured (D). At the time of harvest after 3rd DSS cycle, incidence of macroscopic polyps was analyzed (E). (F) Tumors within the colon were counted with the assistance of stereomicroscopy. (G) Measurement of largest dimension of tumor $(\mathrm{mm})$ was performed using calipers. (H) Ki-67 immunohistochemistry staining (left panel) and percentage of Ki-67 positive cells. Data are shown as the mean \pm s.d and are representative of three independent experiments. ${ }^{*} P<0.05,{ }^{* *} P<0.01,{ }^{* * *} P<0.001$. 
inflammatory response [15]. We therefore used the FITC-labelled dextran method to investigate the colonic permeability of $\mathrm{CK}^{+/-}$mice treated with DSS or AOM/ DSS. Since the gut does not actively absorb FITCdextran, intestinal permeability can be assessed directly in vivo based on the amount of fluorescence in the serum. FITC-dextran was administered to $\mathrm{CK}^{+/-}$mice and WT mice on day 7 after 5\% DSS treatment and on day 60 at the end of the third DSS cycle. As shown in Figure 6A, under conditions with normal drinking water, colonic permeability did not differ significantly between WT and $\mathrm{CK}^{+/-}$mice, whereas with DSS or AOM/DSS treatment, $\mathrm{CK}^{+/-}$mice demonstrated greater colonic permeability (higher levels of fluorescence in the serum) than WT mice. In the presence of 5\% DSS for 7 days, the colonic permeability was about 10 -fold greater in $\mathrm{CK}^{+/-}$ mice than in WT mice. In the CAC model with AOM/ DSS treatment, $\mathrm{CK}^{+/-}$mice displayed 3-fold greater permeability than WT mice (Figure 6B). These results suggest that the greater colonic inflammation and tumor development in $\mathrm{CK}^{+-}$mice is associated with greater colonic permeability.

\section{Fecal microbiota of $\mathrm{CKB}^{+/-}$mice differ from those of WT mice after AOM/DSS treatment}

We next examined whether $\mathrm{CK}^{+/-}$mice predisposed to developing $\mathrm{CAC}$ had different colonic microbiota than WT mice. No obvious difference in fecal microbiota composition was observed between $\mathrm{CK}^{+/-}$mice and WT mice. Then, we treated age-matched ( 8 weeks) and sex-matched $\mathrm{CK}^{+/-}$and littermate WT mice with AOM/ DSS in the same manner discussed above, and harvested fecal samples at the end of the third DSS cycle. The $16 \mathrm{~S}$ ribosomal RNA gene in the fecal samples was sequenced. All the analyzed sequences belonged to Kingdom Bacteria and were assigned to 18 phyla, including Bacteroidetes, Firmicutes, Verrucomicrobia, and Proteobacteria, encompassing the majority of sequences $(>97 \%)$.

From a principal coordinates analysis plot (Figure 7A) based on the predominant genera, we determined that $\mathrm{CK} 8^{+/-}$mice and WT mice each formed a strong single cluster. The fecal microbiota from $\mathrm{CK}^{+/-}$and WT mice were easily distinguished within the primary 3 -axis. The taxa that differed most between the two communities are shown in Figure 7B. Clostridia and Epsilonproteobacteria were enriched in $\mathrm{CRC} \mathrm{CK} 8^{+-}$mice, whereas Bacteroidia and Verrucomicrobia were enriched in CRC WT mice; these were all important class types for segregating the fecal microbiota of WT and $\mathrm{CK}^{+/-}$mice. These data suggest that the fecal microbiota communities are indeed different in $\mathrm{AOM} / \mathrm{DSS}$-treated $\mathrm{CK} 8^{+/-}$and WT mice.

We further compared the gut microbiota between CRC WT mice and $\mathrm{CRC} \mathrm{CK}^{+/-}$mice at different levels. As shown in Figure 7C, at the phylum level, Bacteroidetes and Verrucomicrobia were more abundant in the gut microbiota of CRC WT mice than in those of $\mathrm{CRC} \mathrm{CK8} 8^{+/}$ mice. On the other hand, the abundance of Firmicutes and
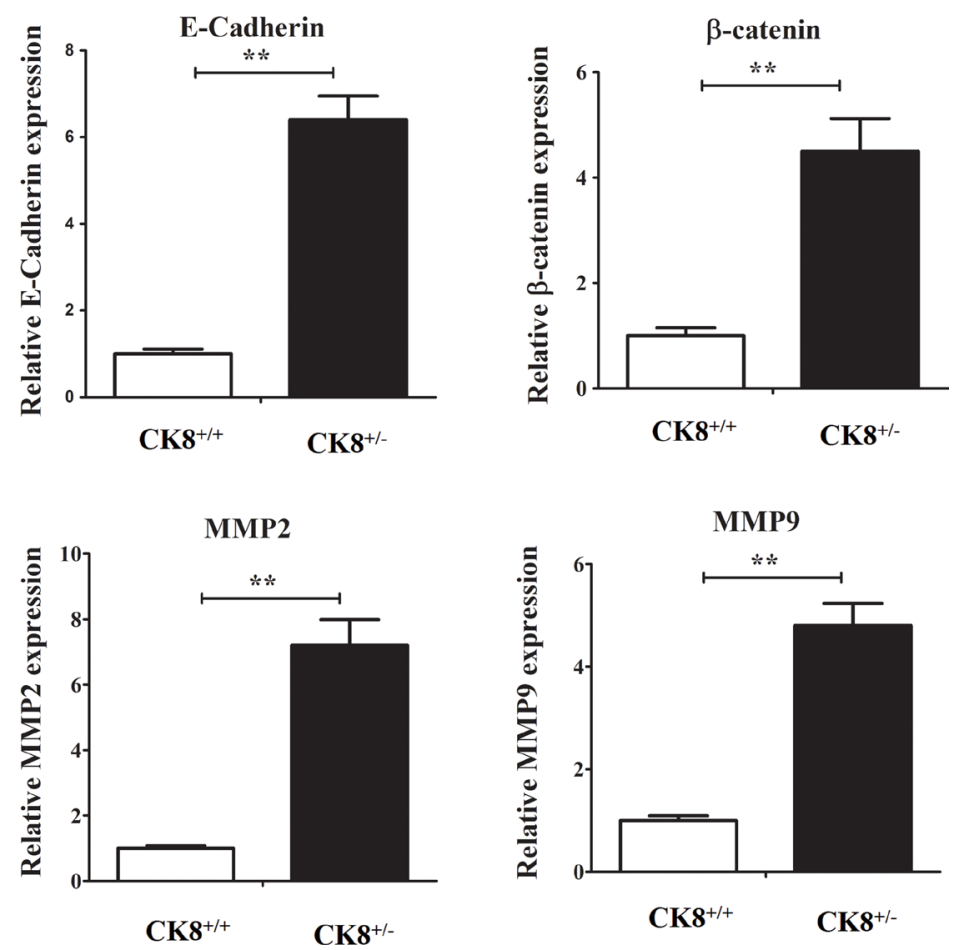

Figure 3: Cancer-related genes mRNA expression in colons of $\mathrm{CK8}^{+/+}$mice and $\mathrm{CK8}^{+/-}$mice with colorectal cancer. $\mathrm{CK}^{+/+}$mice and $\mathrm{CK} 8^{+/-}$mice were treated with AOM/DSS as the above described and then RNA was extracted for real-time PCR analysis. Data are shown as the mean \pm s.d and are representative of five individuals. ${ }^{* *} P<0.01$. 
Proteobacteria was significantly lower in CRC WT mice. At the family level, Bacteroidaceae, Verrucomicrobiaceae and Prevotellaceae were relatively more abundant in CRC
WT mice, while Lachnospiraceae, Ruminococcaceae and Helicobacteraceae were more abundant in $\mathrm{CRC} \mathrm{CK}^{+/-}$ mice (Figure 7D). At the genus level, genera Alloprevotella,
A

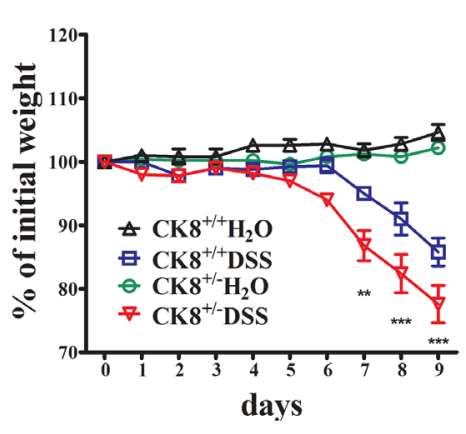

B
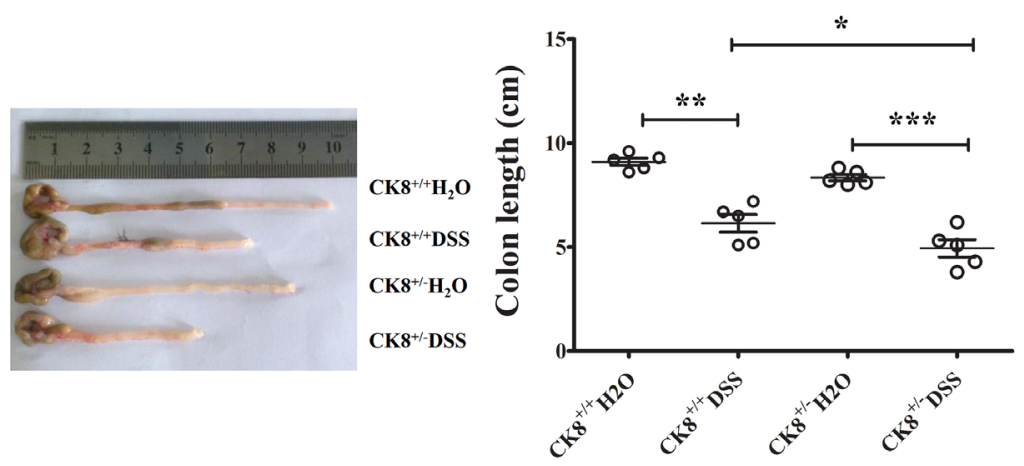

DSS (days) 0

2

4

6
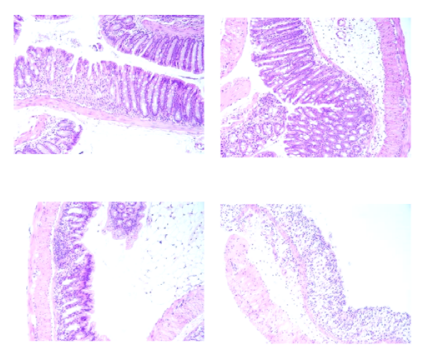

D
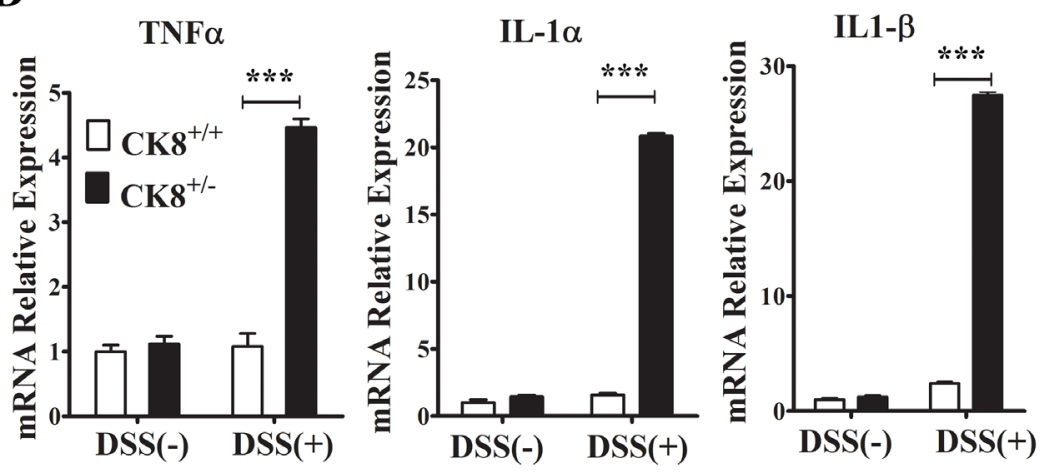
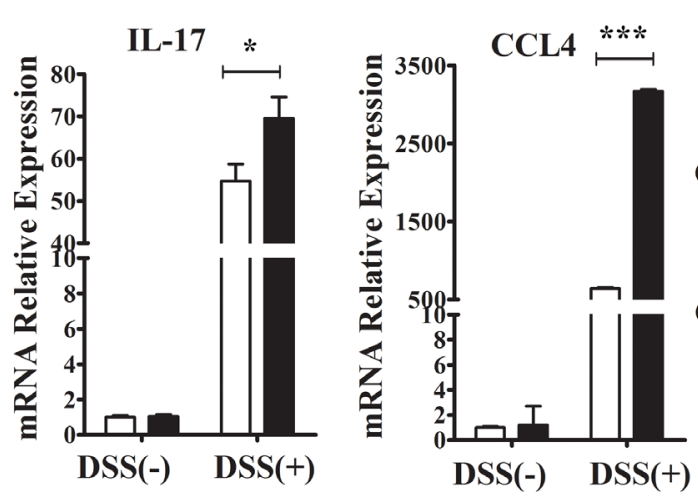

E

(DSs -2 DSS
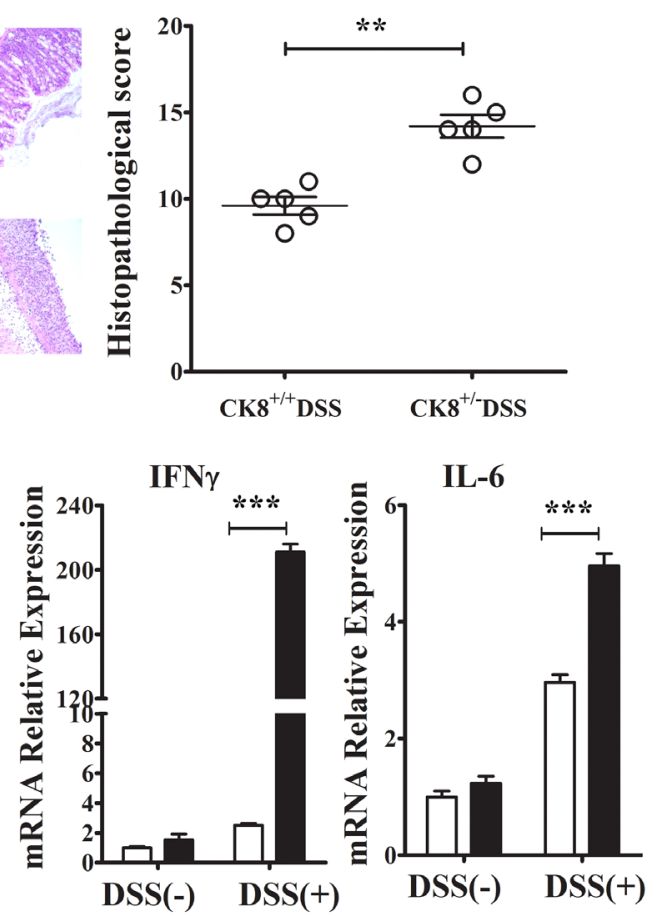

8
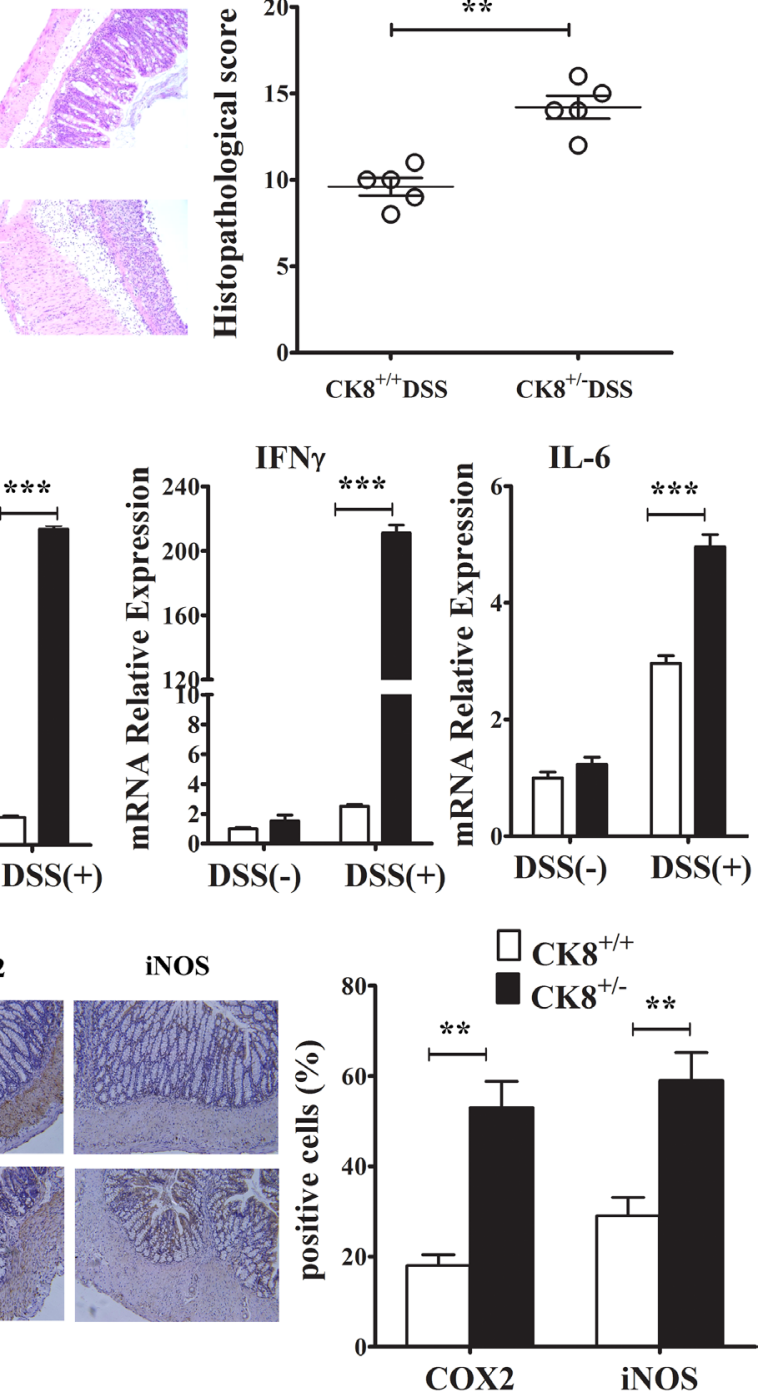

Figure 4: CK8 dampens inflammatory responses after DSS induction. (A) The mean changes in body weight of the CK $8^{+/+}$and $\mathrm{CK}^{+/-}$mice $(n=10$ for each genotype) after being fed with $5 \%$ DSS were measured every day until day 9 . Colon length were measured (B). Histological changes in the colon tissue were examined by H\&E staining (C). Inflammation score of colon tissue was performed as described in materials and methods. (D) The levels of the indicated genes in colons from $\mathrm{CK}^{+/+}$or $\mathrm{CK}^{+/-}$mice were quantified by real-time PCR analysis ( $n=3$ for each group). (E) The levels of COX2 and iNOS in colon tissue ( $n=5$ for each group) mice were measured using immunohistochemistry staining. Data are shown as the mean \pm s.d. ${ }^{*} P<0.05,{ }^{* *} P<0.01,{ }^{* * *} P<0.001$. 
Oscillibacter, and Helicobacter were all enriched in the feces of $\mathrm{CRC} \mathrm{CK}^{+/-}$mice compared with CRC WT mice (Figure 7E), whereas Bacteroides and Akkermansia were enriched in CRC WT mice. Other differences between the WT and $\mathrm{CK}^{+/-}$mice are shown in Supplementary Table 2.

\section{Intestinal depletion of bacteria reduces tumor formation in $\mathrm{CK8}^{+-}$mice}

The pathogenesis of human IBD [21, 22] and colon tumorigenesis [23] have recently been reported to be profoundly influenced by altered gut microbiota. Since $\mathrm{CK} 8^{+/}$mice exhibited greater colonic permeability and different gut microbiota than WT mice following
AOM/DSS treatment, we evaluated whether the greater sensitivity of the $\mathrm{CK}^{+/-}$mice to $\mathrm{CAC}$ depended on commensal bacteria. $\mathrm{CK} 8^{+/-}$mice were treated with an antibiotic cocktail for one month, which remarkably depleted their anaerobic intestinal bacteria (the majority of the gut microbiota; data not shown). Then, AOM/DSS was used to stimulate tumorigenesis, as previously described. Consistent with previous reports, the administration of an antibiotic cocktail increased the mortality following DSS treatment, confirming the importance of the gut microbiota for intestinal homeostasis [24, 25]. As seen in Figure $8 \mathrm{~A}$ and $8 \mathrm{~B}$, the depletion of intestinal bacteria by antibiotic treatment of $\mathrm{CK}^{+/-}$mice dramatically suppressed colon tumor formation.
A

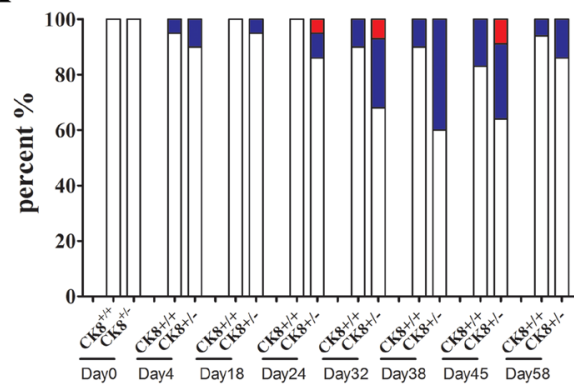

B

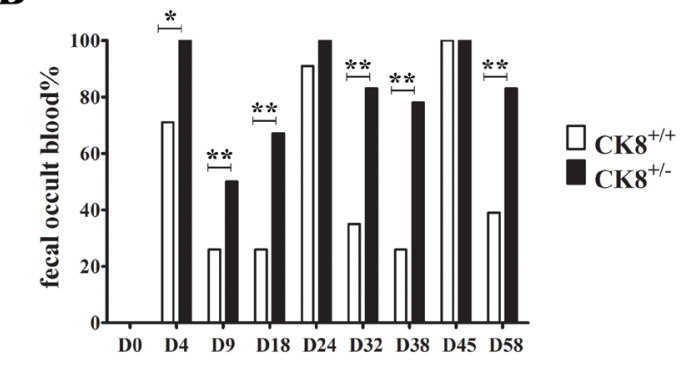

B
C<smiles></smiles>

$\mathrm{CK8}^{+/+}$

D

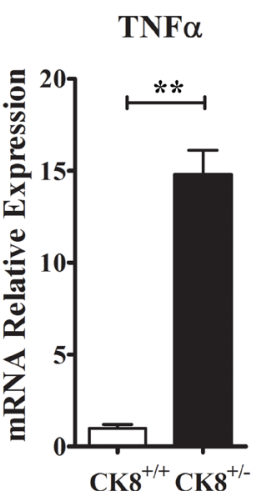

Cycle 1

$\mathrm{CK}^{+/-}$
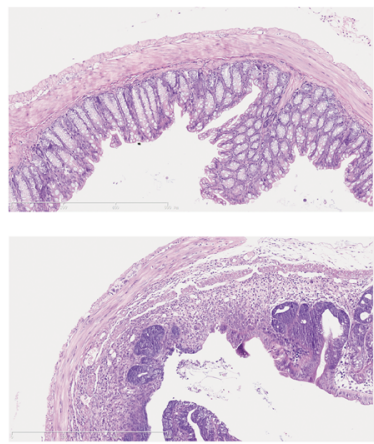

IFNy

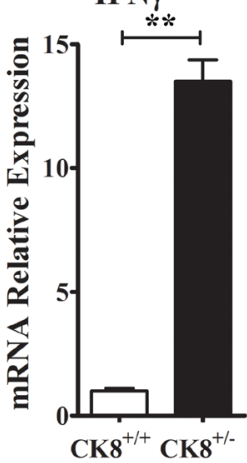

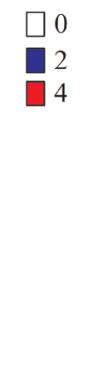

Cycle 2
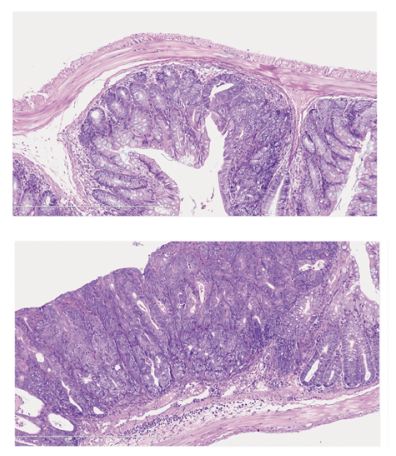

Cycle 3
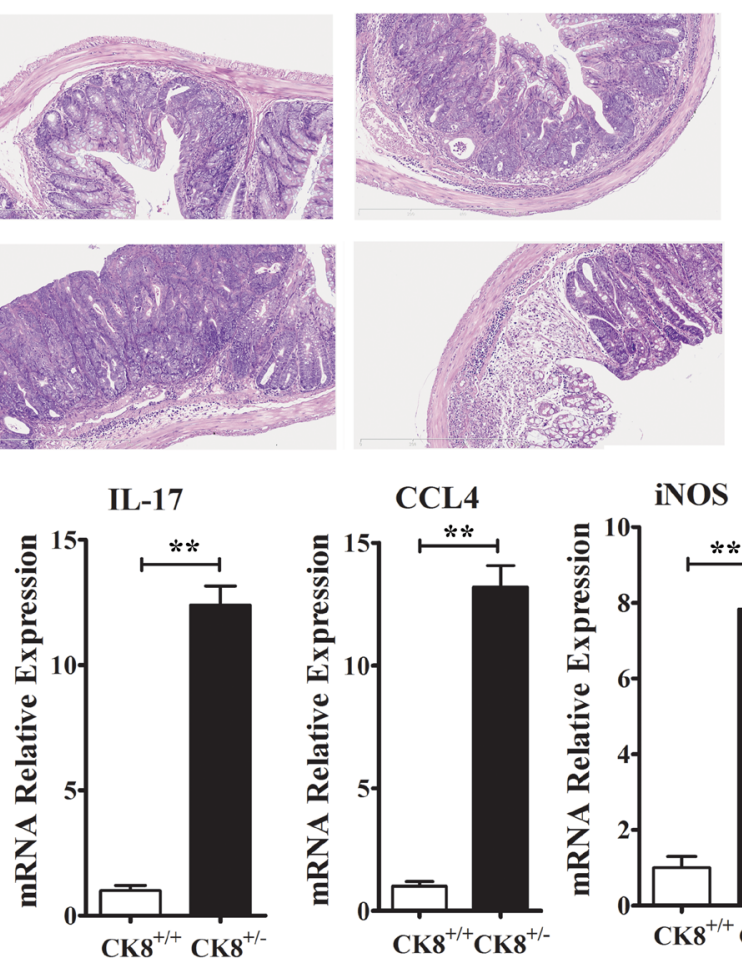

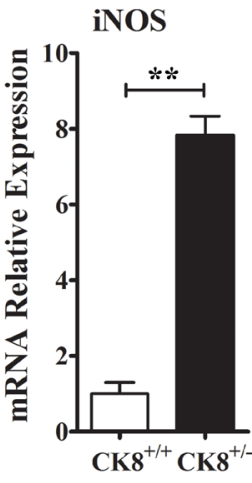

Figure 5: Increased inflammatory response in $\mathrm{AOM} / \mathrm{DSS}$-treated $\mathrm{CK8}^{+/-}$mice compared to $\mathrm{CK8}^{+/+}$mice. $(\mathrm{A}) \mathrm{CK}^{+/+}$mice and $\mathrm{CK}^{+/-}$mice ( $n=12$ for each group) were treated with AOM/DSS as the above described. The diarrhea score (A), the percent of fecal occult blood positive mice (B) were analyzed. Histological changes in the colon tissue were examined at the end of each DSS cycle (C). (D) The mRNA expression of inflammatory cytokines indicated were quantified by real-time PCR analysis ( $n=3$ for each group). Data are shown as the mean \pm s.d. ${ }^{*} P<0.05,{ }^{* *} P<0.01$. 
These results indicate that the gut microbiota might have contributed to the increased colitis and colitisassociated tumorigenesis in $\mathrm{CK}^{+/-}$mice.

\section{TLR4 inhibitor treatment reduces the vulnerability of $\mathrm{CK8}^{+-}$mice to colitis induced by DSS}

As described above, the phylum Proteobacteria was significantly upregulated in $\mathrm{CRC} \mathrm{CK}^{+/-}$mice. Within Proteobacteria, the Epsilonproteobacteria class, Campylobacterales order and Helicobacteraceae family were all significantly more abundant in $\mathrm{CRC} \mathrm{CK} 8^{+/-}$mice than in CRC WT mice. Previous studies have suggested that Proteobacteria species are elevated in colitis [26] and CAC [27]. Infection with different Helicobacter spp. led to CAC development, suggesting that Helicobacter spp. in particular promote CRC tumorigenesis [28]. Given that Helicobacteraceae are classified as gram-negative bacteria, we investigated the lipopolysaccharide (LPS) levels from these bacteria in the serum of DSS-induced $\mathrm{CK}^{+/-}$mice and WT mice. As shown in Figure 9A, during DSS-induced colitis, the LPS levels were significantly higher in $\mathrm{CK}^{+/-}$mice than in WT mice.

Our previous study suggested that CK8 suppressed TLR/Nuclear Factor Kappa B (NF- $\mathrm{B}$ ) signaling by preventing the polyubiquitination of TNF Receptor Associated Factor 6 (TRAF6). Thus, we investigated the transcriptional activity of NF- $\kappa \mathrm{B}$ in colonic tissue from mouse models of DSS-induced acute colitis and AOM/ DSS-induced CRC. As expected, colonic NF- $\kappa \mathrm{B}$ activity in DSS-induced colitis and CRC was significantly higher in $\mathrm{CK}^{+/-}$mice than in WT mice (Figure 9B), suggesting that the downregulation of CK8 increases the activation of $\mathrm{NF}-\kappa \mathrm{B}$ in association with more severe inflammation.
We further assessed whether TLR signaling enhanced the vulnerability of $\mathrm{CK}^{+/-}$mice to DSS-induced colitis. $\mathrm{CK}^{+/-}$mice and WT mice were treated with TAK242 (a small-molecule inhibitor that specifically binds to the intracellular domain of TLR4 and thus prevents LPS from stimulating the generation of inflammatory mediators), given a 5\% DSS solution in their drinking water for 5 days, and then given normal drinking water for 3 days. The severity of colitis was evaluated based on the colon length, histological injury score, and inflammatory cytokine expression. As shown in Figure 9C and 9D, the shorter colon length in the $\mathrm{CK}^{+/-}$strain after DSS treatment was reversed by TAK-242 treatment. When we histologically analyzed colons stained with H\&E, we found further evidence that colon injury in $\mathrm{CK}^{+/-}$ mice was attenuated by TAK-242 treatment (Figure 9E). Furthermore, the colonic levels of TNF $\alpha$ and IFN $\gamma$ were significantly lower in mice treated with TAK-242 than in mice without TAK-242 treatment (Figure 9F). These results suggest that TLR4/NF- $\mathrm{KB}$ signaling enhances the susceptibility of $\mathrm{CK}^{+/-}$mice to DSS-induced colitis.

\section{DISCUSSION}

There is increasing evidence that CK8 may be an important signaling molecule regulating the inflammatory response. Our previous study indicated that CK8 prevented the polyubiquitination of TRAF6, thus suppressing NF- $\kappa$ B signaling and TLR-dependent inflammation [14]. In addition, chronic colitis was found to occur spontaneously in homozygous $\mathrm{CK}^{-/-} \mathrm{FVB} / \mathrm{N}$ mice [9]. In the present study, we demonstrated that knockdown of CK8 increased the vulnerability of mice to DSS-induced acute colitis and promoted AOM/DSS-induced CAC at a very early stage. $\mathrm{CK}^{+/-}$mice exhibited increased colonic permeability and an abnormal gut microbiota composition, while
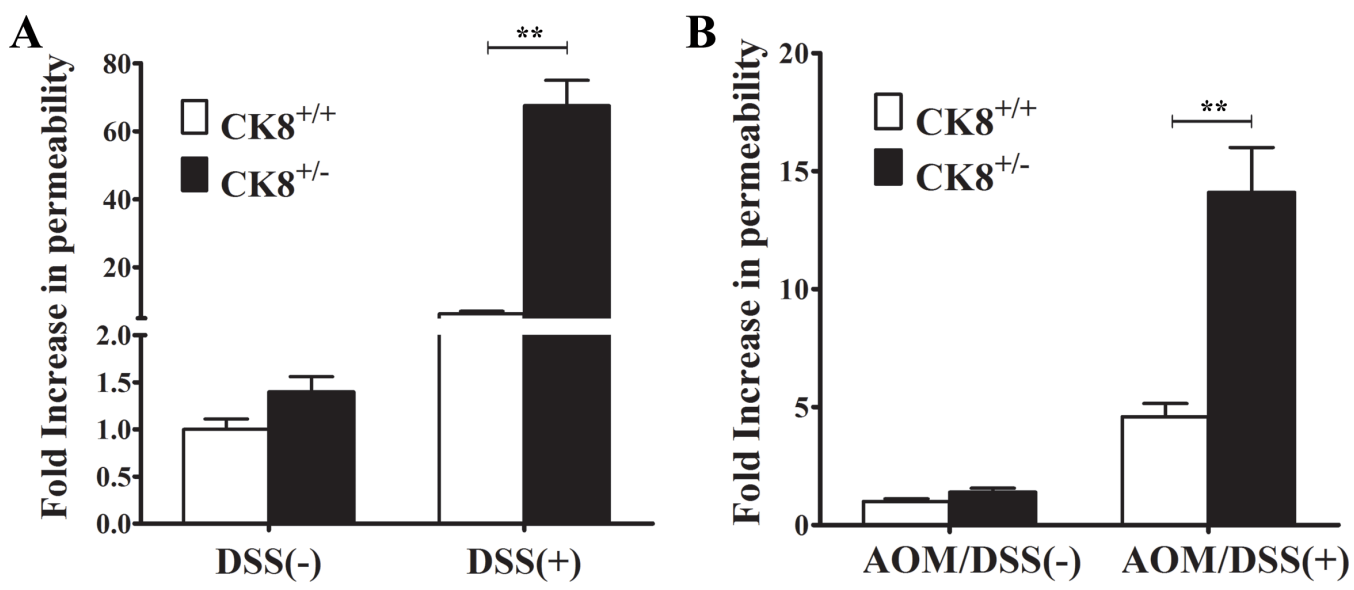

Figure 6: $\mathrm{CK8}^{+-}$mice exhibit increased colonic permeability during DSS-induced colitis and AOM/DSS-induced colorectal carcinogenesis. (A) $\mathrm{CK}^{+/+}$mice and $\mathrm{CK}^{+/-}$mice were treated with 5\% DSS as above described and on day 7 FITC-dextran permeability assay was performed ( $n=4$ for each group). (B) $\mathrm{CK}^{+/+}$mice and $\mathrm{CK} 8^{+/-}$mice were treated with AOM/DSS as above described and on day 60 at the end of 3rd DSS cycle FITC-dextran permeability assay was performed ( $n=4$ for each group). Data are shown as the mean \pm s.d. ${ }^{* *} P<0.01$. 
A

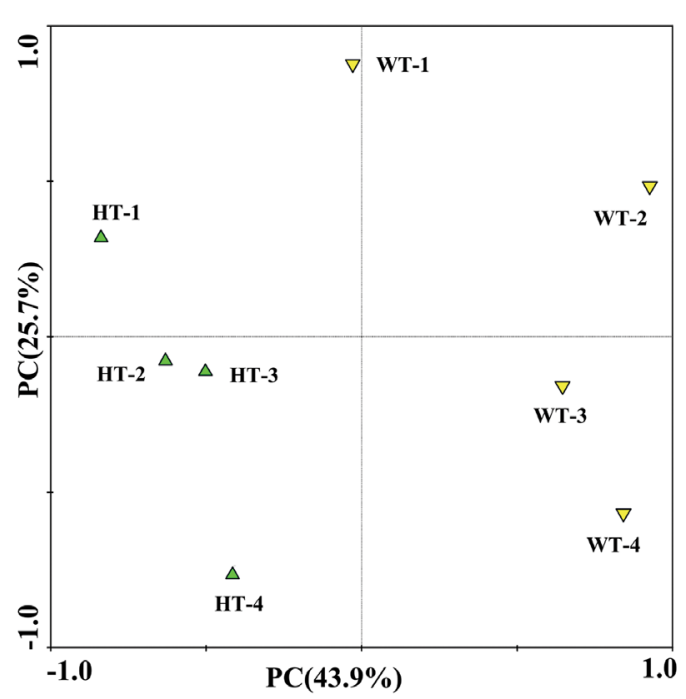

C

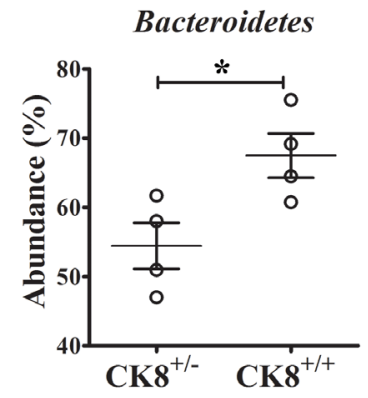

D

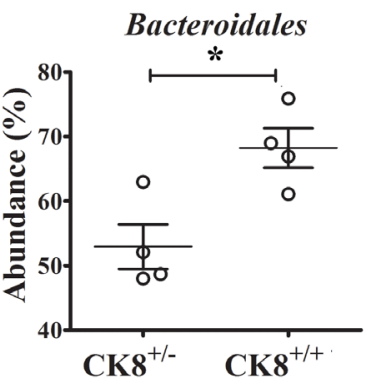

$\mathbf{E}$

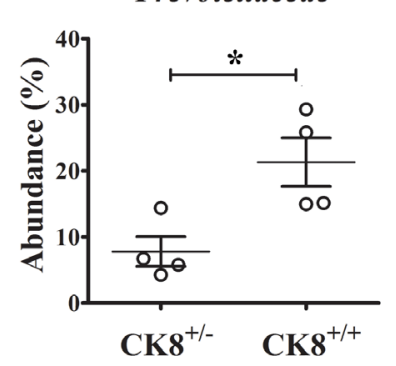

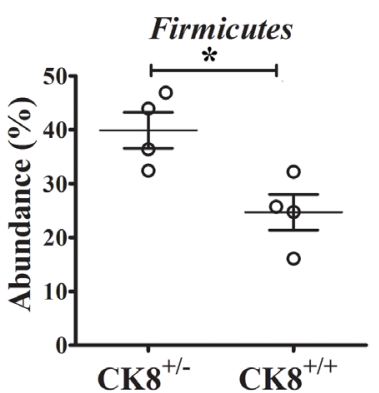

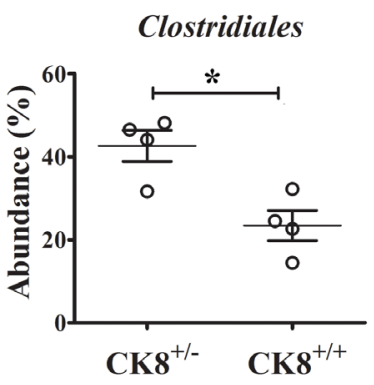

Ruminococcaceae

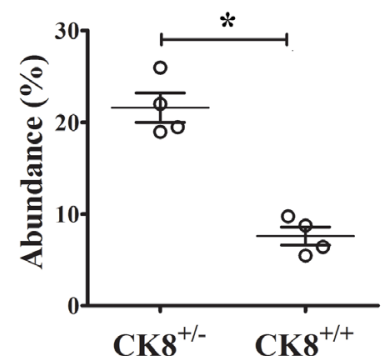

\section{B}

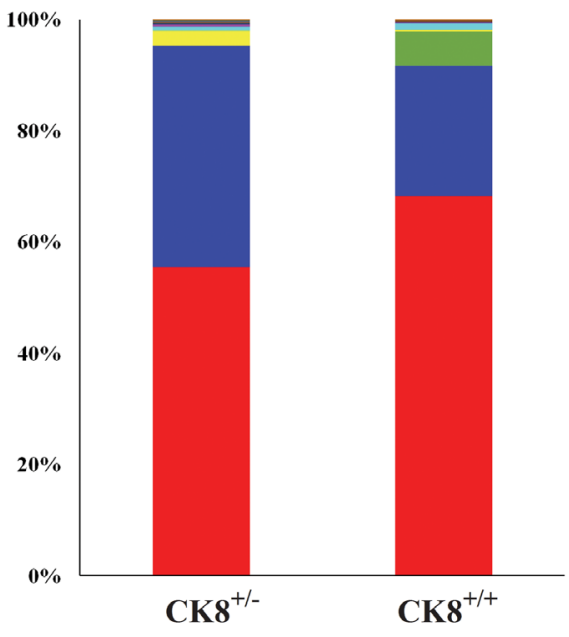

Verrucomicrobia
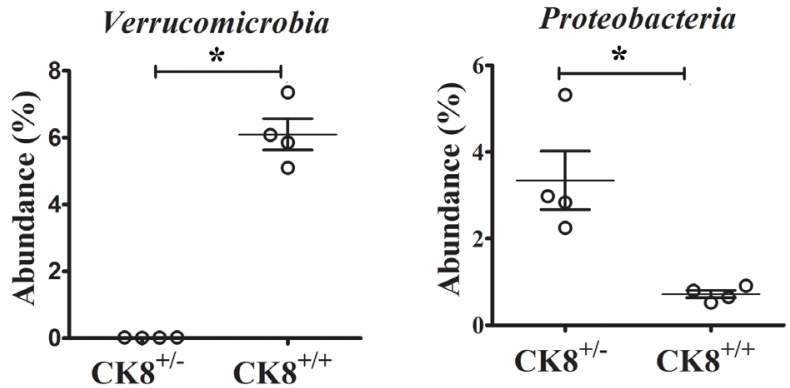

Verrucomicrobiales

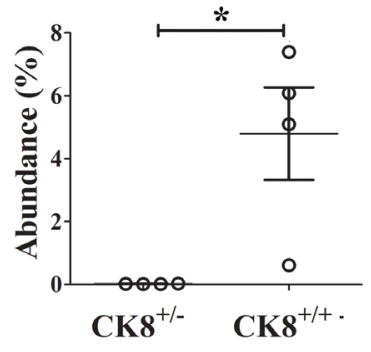

Verrucomicrobiaceae

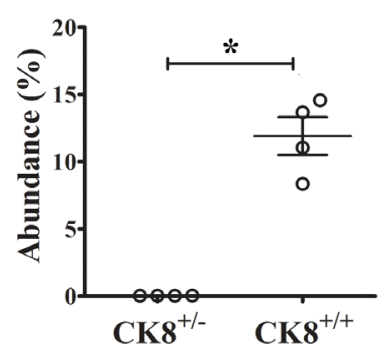

- Bacteroidia

n Clostridia

- Verrucomicrobiae

Epsilonproteobacteria

Bacilli

- Actinobacteria

- Mollicutes

- Alphaproteobacteria

- Deltaproteobacteria

- Deferribacteres

Betaproteobacteria

Figure 7: Fecal microbiota of $\mathbf{C K 8}^{+/-}$mice is distinguished from that of WT mice after AOM/DSS treatment. The agematched ( 8 weeks) and sex-matched $\mathrm{CK}^{+/-}$and littermate WT mice were treated with AOM/DSS as described above, then at the end of the 3rd DSS cycle, fecal samples were harvested. The 16S ribosomal RNA gene in the fecal samples was sequenced. (A) Principal coordinates analysis (PCA) scores plot based on the relative abundance of OTUs (97\% similarity level). (B) Histogram represents the relative abundance of bacterial class in each group $(n=4$ for each group). The abundance of major bacteria at the phylum (C), order (D), and family $(\mathbf{E})$ was analyzed. Each dot represents an individual microbiota sample from the mice. Horizontal bars indicate mean values. ${ }^{*} P$ $<0.05$, Mann-Whitney $U$ test. $n=4$ per group. 
antibiotic treatment reduced the tumor incidence in this strain. Furthermore, the TLR4-specific inhibitor TAK242 reduced the incidence of colitis upon DSS treatment. These data indicated that CK8 prevents colitis and colonic tumorigenesis by protecting the colonic integrity and maintaining gut microbiota homeostasis.

Various lines of evidence suggest that keratins are key regulators of epithelial integrity. Keratin expression and organization are transcriptionally and posttranslationally modified under different stress conditions, thus re-establishing the equilibrium in tissues. Keratins are the main sources of mechanical integrity in keratinocytes, even when just one pair of keratins is expressed [29]. Keratin 9 is required for terminal differentiation and for maintaining the structural integrity of the palmoplantar epidermis [30]. Furthermore, CK8 is needed to preserve the thymic epithelial structure and integrity (in association with CK18) [31].

Disturbances in the epithelial barrier are frequently associated with diseases of the intestines, including IBD. When epithelial cells fail to form an effective barrier, the immune system may become sensitized to luminal antigens [32] [16]. Wang et al. performed experiments in Caco2-BBE cells and IL- $6^{-/}$mice, and found that IL-6 increased CK8 and CK18 levels in the insoluble cytoskeletal fraction and promoted the serine 431 and 73 phosphorylation of CK8, indicating that IL-6 may induce the post-translational modification of CK8 [15]. DSS treatment of IL- $6^{--}$mice enhanced their intestinal permeability, suggesting that IL-6 may regulate barrier function through CK8 [15]. In the present study, we found that $\mathrm{CK} 8$ was downregulated and the colonic permeability of $\mathrm{CK}^{+/-}$mice was elevated during DSS-stimulated colitis and $\mathrm{AOM} / \mathrm{DSS}$-stimulated CAC, suggesting that CK8 is a key promoter of colonic epithelial integrity.

We hypothesize that, due to the enhanced colonic permeability caused by DSS or AOM/DSS treatment, bacteria can translocate into the intestinal mucosa of $\mathrm{CK}^{+-}$mice and induce an exacerbated inflammatory cytokine response. Various studies have indicated that bacteria are involved in the pathogenesis of CRC [33]. Imbalances in microbiota can promote colon tumorigenesis through many pathways. The enterotoxigenic Bacteroides fragilis can cause colitis, colonic hyperplasia, and tumor formation by activating STAT3- and TH17-dependent pathways [34]. Erdman et al. demonstrated that Rag- $2^{-/}$mice developed CAC only upon infection with Helicobacter hepaticus [35]. In another study, vancomycin and imipenem antibiotic treatments suppressed inflammation in the $\mathrm{CK}^{-/-}$colon, indicating that bacteria in the lumen may induce colitis when there is a primary defect of the epithelium [9].

In the present study, the gut microbiota composition differed between $\mathrm{CK}^{+/-} \mathrm{CRC}$ mice and $\mathrm{CK}^{+/+} \mathrm{CRC}$ mice, and treatment with antibiotics reduced the development of CRC. Phyla Firmicutes and Proteobacteria were more abundant in $\mathrm{CRC} \mathrm{CK}^{+/-}$mice, while phyla Bacteroidetes and Verrucomicrobia were more abundant in $\mathrm{CRC} \mathrm{CK8^{+/+ }}$ mice. In a study of an experimental CRC rat model, Firmicutes, Proteobacteria, and Actinobacteria were more abundant in the intestinal lumens of CRC rats than in those of healthy rats, whereas Bacteroidetes were more

A
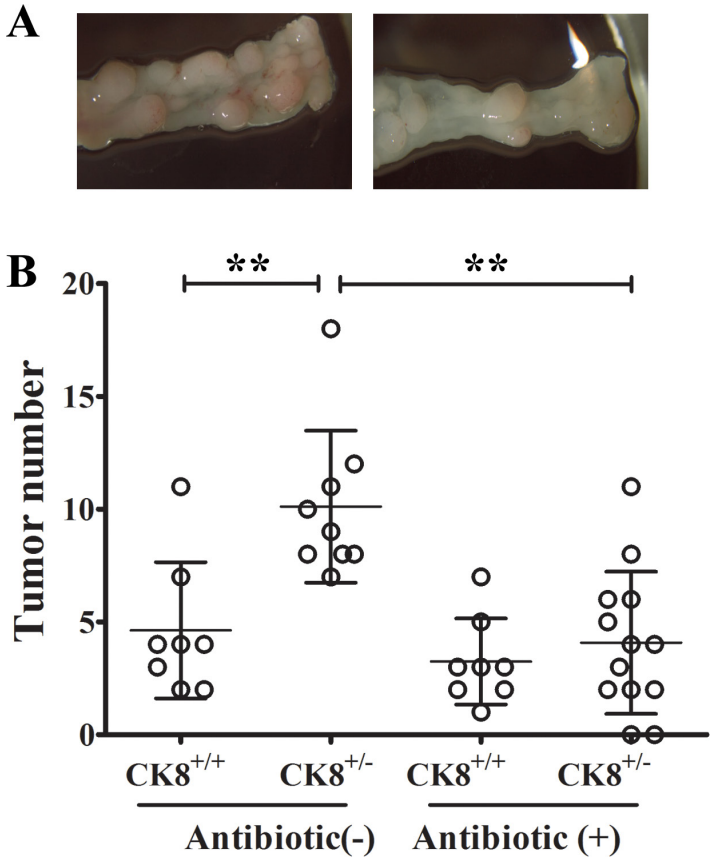

Figure 8: Intestinal depletion of bacteria reduces tumor formation in $\mathbf{C K 8}^{+/-}$mice. $\mathrm{CK} 8^{+/-}$and $\mathrm{CK} 8^{+/+}$mice were treated with an antibiotic cocktail for one month and then induced to colorectal cancer with AOM/DSS. Tumors within the colon were counted. CK $8^{+/-}$ mice treated with antibiotic group, $n=13$; other groups, $n=8$. Data are shown as the mean \pm s.d. ${ }^{* *} P<0.01$. 
abundant in the healthy group [36]. Similar findings were obtained in a human study of CRC patients and cancer-free controls [37]. Firmicutes are the major butyrate-producing bacteria, and butyrate has been suggested to stimulate the excessive colonic epithelial cell proliferation in the $\mathrm{APC}^{\mathrm{Min} /} \mathrm{MSH}^{-/-}$mouse (a model of colon cancer) [38].

The abundance of Verrucomicrobia phylum Akkermansia genus was reduced in $\mathrm{CRC} \mathrm{CK} 8^{+/-}$mice. A previous study suggested that healthy individuals have high levels of Akkermansia muciniphila (which degrades mucin), while humans with inflammatory diseases of the gastrointestinal tract and mice with obesity or type 2 diabetes have lower levels of these bacteria [39]. Interestingly, our study indicated that bacteria of the
Proteobacteria phylum Helicobacteraceae family Helicobacter genus were significantly more abundant in $\mathrm{CRC} \mathrm{CK}^{+/-}$mice than in $\mathrm{CRC} \mathrm{CK}^{+/+}$mice. The abundance of Helicobacteraceae has been reported to be elevated in IBD patients [40], and Helicobacter pylori has been shown to be an independent risk factor for early and advanced colorectal neoplasms [41] and colonic adenomatous neoplasms [42]. Overall, our data indicated that the CK8 knockdown led to an imbalance of the gut microbiota composition under stress conditions, and that the gut microbiota composition was a critical contributor to the colitis and increased tumor incidence of $\mathrm{CK}^{+/-}$mice. However, to identify the commensal bacteria responsible for colorectal cancer development in
A

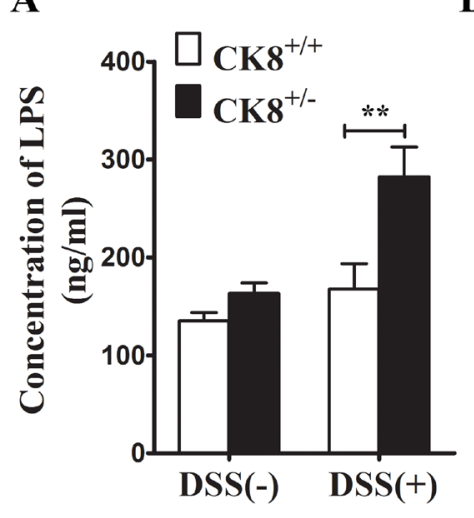

B

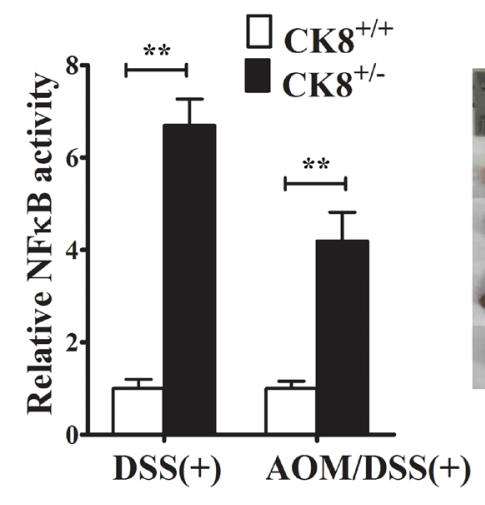

D
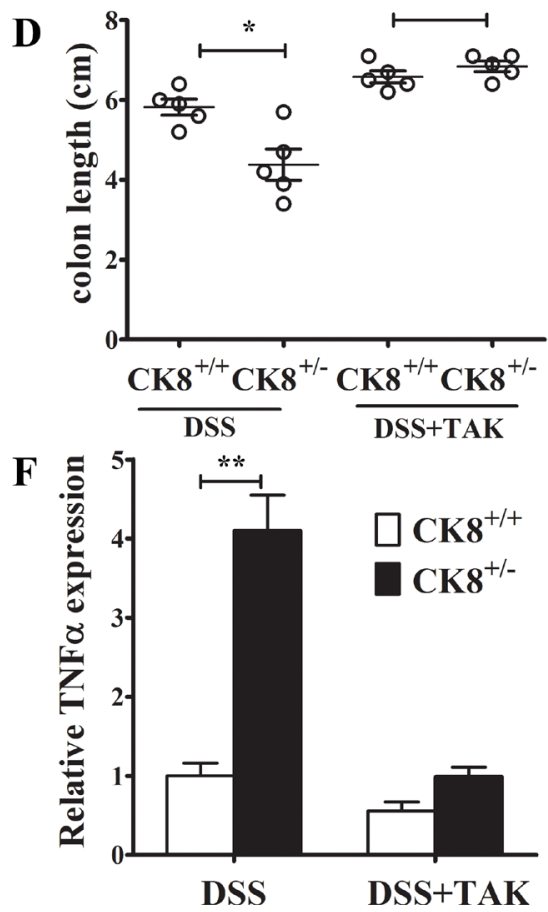

$\mathbf{E}$
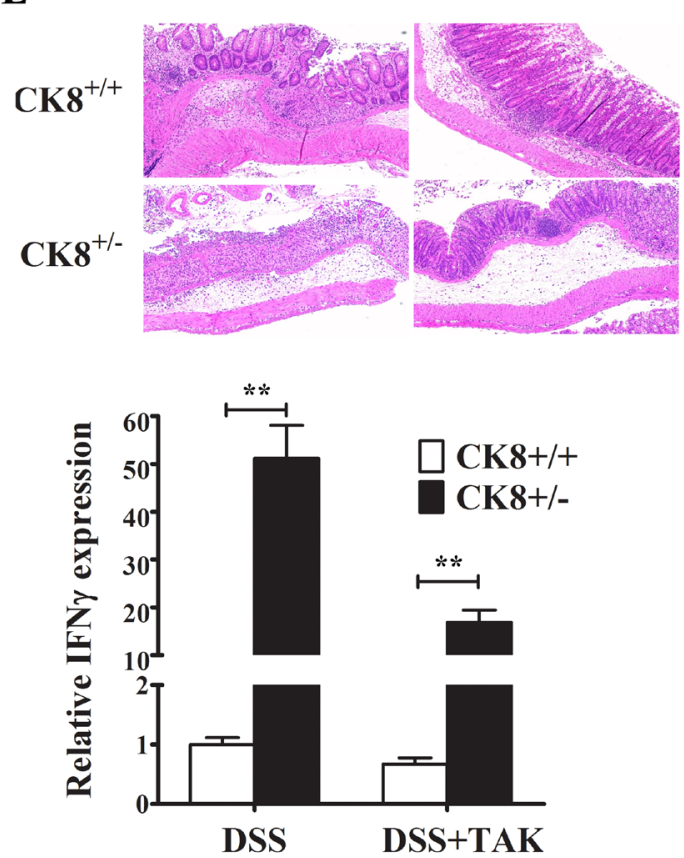

Figure 9: TLR4 inhibitor treatment reduced the susceptibility of $\mathrm{CK8}^{+/-}$mice to DSS-induced colitis. $\mathrm{CK}^{+/-}$and $\mathrm{CK} 8^{+/+}$ mice were treated with DSS as above described. The serum lipopolysaccharide (LPS) level was investigated (A). (B) NF- $\kappa B$ activity in colonic tissue from DSS or AOM/DSS treated $\mathrm{CK} 8^{+/-}$and $\mathrm{CK} 8^{+/+}$mice were measured.(C) TAK-242 were administered intravenously at the dose of $1 \mathrm{mg} / \mathrm{kg}$ to $\mathrm{CK}^{+/-}$and $\mathrm{CK}^{+/+}$mice. Then the mice were fed $5 \%$ DSS-solution in drinking water for 5 days, followed by regular drinking water for 3 days. The severity of colitis was evaluated with colon length (D), histological injury (E), and expression levels of inflammatory cytokines $(\mathbf{F})$. Data are shown as the mean \pm s.d. ${ }^{*} P<0.05,{ }^{* *} P<0.01 . n=5$ for each group. 
$\mathrm{CK}^{+/-}$mice, a further study with a specific antibiotic will be required.

Widespread maladies (e.g., Helicobacter pylori infection and gastric cancer) may chronically induce infection and inflammation and subsequently activate TLR4 [43]. Our study demonstrated that, upon DSS treatment, the serum concentration of LPS (the ligand for TLR4) was much higher in $\mathrm{CK}^{+/-}$mice than in $\mathrm{CK}^{+/+}$ mice. NF- $\kappa \mathrm{B}$ activity was also enhanced in $\mathrm{CK}^{+/-}$mice following DSS or AOM/DSS treatment. There is sufficient evidence that TLR4 is a key inducer of colitis and CAC. TLR4 is overexpressed in colon tumors resulting from chronic ulcerative colitis in humans and from inflammation in animals [44]. In acute colitis, TLR4 strongly stimulates the expression of COX2 [45]. Inflammation-induced colon cancer was prevented by the genetic ablation of Tlr 4 in mice [44]. Our study suggested that CK8 negatively regulates $\mathrm{TLR} / \mathrm{NF}-\mathrm{\kappa B}$ signaling, and that $\mathrm{CK} 8^{+-}$mice are more susceptible to LPS/TLR4-induced inflammatory responses than WT mice. The specific TLR4 inhibitor, TAK-242, significantly attenuated the severity of DSSinduced colitis in $\mathrm{CK}^{+/-}$mice, suggesting that TLR4/NF$\kappa \mathrm{B}$ signaling may be involved in the inflammatory response to microbiota and may further promote tumor formation.

In summary, our results support the concept that, under stress conditions, intact CK8 expression is critical for maintaining the intestinal epithelial barrier and gut microbiota homeostasis. Dysregulation of CK8 leads to uncontrolled inflammatory responses and increased CAC development.

\section{MATERIALS AND METHODS}

\section{Ethics statement}

Investigation has been conducted in accordance with the ethical standards and according to the Declaration of Helsinki and according to national and international guidelines and has been approved by the Animal Ethics Committee of the Beijing Institute of Radiation Medicine.

\section{Cell lines and reagents}

HT29 cells were maintained in DMEM (Gibco Invitrogen, CA) with 10\% fetal calf serum (FCS). All the cells were cultured in a $37^{\circ} \mathrm{C}$ incubator with $5 \% \mathrm{CO}_{2}$ in the presence of $2 \mathrm{mM}$ glutamine, $100 \mathrm{IU} / \mathrm{ml}$ penicillin, $100 \mathrm{mg} / \mathrm{ml}$ streptomycin, $2 \mathrm{~g} / 1$ sodium bicarbonate and 10 mM HEPES.

\section{Mice}

All mice were bred in a specific pathogen-free facility, and all animal experiments were approved by the Animal Ethics Committee of the Academy of Military Medical Science.

\section{DSS-induced colitis}

Colitis was induced in $\mathrm{CK} 8^{+/+}$and $\mathrm{CK}^{+/-}$mice by administering 5\% (wt/vol) DSS (36-50 kD; MP Biomedical) that was dissolved in drinking water for five consecutive days as described previously, followed by regular water [45].

\section{Western blotting analysis}

For Western blotting, cells were lysed with M-PER ${ }^{\circledR}$ Mammalian Protein Extraction Reagent (Pierce, Rockford, IL, USA). Then, Western blot analysis was performed according to standard procedures. Antibodies were used at the following concentrations: CK8 (ab53280, Abcam), 1:3000; GAPDH (sc-47778, Santa Cruz), 1:1000. Chemiluminescent detection was conducted using supersignal substrate (Pierce) according to the manufacturer's specifications.

\section{Quantitative real-time RT-PCR}

Total RNA was reverse-transcribed and amplified using reverse transcription and PCR kits, respectively (Promega Corp., Madison, WI, U.S.). Real-time RT-PCR was performed by Bio-Rad IQ5 (Bio-Rad, U.S.). The abundance of mRNA of each gene was normalized to GAPDH. The sequences of the primers are provided in Supplementary Table 1.

\section{Intestinal permeability}

Mice were anaesthetised and 100 microliters of 80 $\mathrm{mg} / \mathrm{ml}$ FITC-dextran solution was delivered via rectal enema. Mice were inverted for $30 \mathrm{~min}$ prior to sacrificing and harvesting blood via cardiac puncture. Blood was allowed to clot followed by centrifugation and serum harvesting. Samples were read at 480 and $520 \mathrm{~nm}$ on a Microplate Reader (EnSpire, PerkinElmer, USA).

\section{Collection of tissue specimens}

Human tissue specimens were obtained from surgical resections and biopsies in accordance with human studies guidelines and approval by the ethics committee of the Beijing Institute of Radiation Medicine. Clinical data was recorded from medical records and then the identifying information was removed. Tissues for immunohistochemical use were fixed in buffered formalin and embedded in paraffin using standard methods. Normal colon specimens were obtained from patients undergoing colonoscopy and who had normal colonoscopic exams and normal histology.

\section{Immunohistochemistry}

The slides were baked at $60^{\circ} \mathrm{C} 2$ hours and then deparaffinized by washing in xylene $(2 \times 10 \mathrm{~min})$. Sections 
were hydrated through graded alcohol and endogenous peroxidase activity was quenched by incubating the sections in $3 \% \mathrm{H}_{2} \mathrm{O}_{2}$ in methanol for $30 \mathrm{~min}$. After further washing with tap water for $15 \mathrm{~min}$, antigen retrieval was done by heating the slides in citrate buffer $(0.01 \mathrm{M}, \mathrm{pH}$ 6.0 ) at $92 \sim 98^{\circ} \mathrm{C}$ for $15 \mathrm{~min}$. After heating, the samples were allowed to cool at room temperature. This was followed by washing with phosphate-buffered saline (PBS) $(3 \times 5 \mathrm{~min})$. Non-specific binding was blocked by incubating the sections with $10 \%$ normal goat serum for $30 \mathrm{~min}$. Sections were then incubated with anti-CK8 antibody $(1: 300)$ at $4{ }^{\circ} \mathrm{C}$ overnight. Then slides were washed with phosphate buffered saline $(3 \times 5 \mathrm{~min})$ and incubated with secondary antibody auxiliary regent for 30 min. Then sections were washed with phosphate buffered saline $(3 \times 5 \mathrm{~min})$ and incubated with secondary antibody (PV-9001, ZSGB-Bio, China) $30 \mathrm{~min}$.Then sections washed with PBS $(3 \times 5 \mathrm{~min})$ followed by treatment with DAB reagent (Wuhan Boster Biological Technology Ltd., China). After washing with PBS, counterstaining was done using haematoxylin. With further washing in tap water, sections were dehydrated in graded alcohol and covered with cover glass.

\section{AOM/DSS-induced colon tumorigenesis}

8-12-week-old mice were injected intraperitoneally (i.p.) with $10 \mathrm{mg} / \mathrm{kg}$ azoxymethane (Sigma). Water containing 2\% dextran sulfate sodium (MP Biomedicals, 36-50 kD) was fed on day 5 for 5 days followed by 16 days of water. This was repeated twice. Mice were sacrificed 3 weeks after the end of the third cycle of DSS or at the end of 10 weeks. After sacrifice, colons were harvested, flushed of feces and longitudinally slit open to grossly count tumors with the aid of a magnifier and stereomicroscope.

\section{Depletion of gut microbiota}

Mice were initially given a four week treatment of $1 \mathrm{~g} / \mathrm{L}$ ampicillin, $0.5 \mathrm{~g} / \mathrm{L}$ vancomycin, $1 \mathrm{~g} / \mathrm{L}$ metronidazole and $1 \mathrm{~g} / \mathrm{L}$ neomycin for 4 weeks. Due to only modest intestinal depletion as assayed by fecal cultures, mice were subsequently switched over to a different antibiotic cocktail of $2 \mathrm{~g} / \mathrm{L}$ streptomycin, $0.17 \mathrm{~g} / \mathrm{L}$ gentamycin, $0.125 \mathrm{mg} / \mathrm{L}$ ciprofloxacin and $1 \mathrm{~g} / \mathrm{L}$ bacitracin which was maintained for the duration of the experiment. Intestinal depletion was assessed by collecting feces, homogenizing in PBS, serially diluting and plating on trypticase soy agar with $10 \%$ sheep blood (Fisher Scientific) for 48 hours at $37^{\circ} \mathrm{C}$ aerobically and in anaerobic chamber (AnaeroPack System).

\section{Metagenomic analysis of fecal sample microbiota}

Genomic DNA was isolated from approximately $100 \mathrm{mg}$ of fecal samples which were harvested from
$\mathrm{CK} 8^{+/-}$and littermate WT mice at the end of the third DSS cycle using the TIANamp Stool DNA kit (DP328-02, TIANGEN, China) following the manufacturer's instruction. The $16 \mathrm{~S}$ ribosomal RNA gene in the fecal samples was sequenced by Anoroad Ltd.(China). DNA library construction was performed using the IlluminaHiseqTM2500. Adaptor contamination, lowquality reads, and host contaminating reads were removed from the raw sequencing reads sets. 0.366 million $\left(\mathrm{CK}^{+/-}\right.$mice) and 0.357 million (WT- mice) high-quality reads per sample were generated for further analyses. The reads with sequence similarity greater than $97 \%$ were classified as a class of OTUs (Operational Taxonomic Units). Then Cluster analysis of OTUs was carried out by Uclust 1.1.579.

\section{Examination of NF- $\kappa \mathrm{B}$ activity}

Extraction of nuclear protein from different colon tissues which treated by DSS or AOM/DSS. Then exam the NF- $\kappa \mathrm{B}$ activity using the NF- $\kappa \mathrm{B}$ p65 Transcription Factor Assay Kit(ab133112 abcam) following the manufacturer's instruction. Read absorbance at $450 \mathrm{~nm}$ by Microplate Reader (EnSpire, PerkinElmer, USA).

\section{Inflammation score}

Colons from mice were fixed in $10 \%$ (vol/vol) neutral formalin. Paraffin-embedded tissues were cut into sections and stained with hematoxylin and eosin. Inflammation score of histopathologic changes in the colonic were semi-quantified according to a modified scoring system [46]:(a) cellular infiltration in the lamina propria (scored from 0 to 4 ); (b) thickness of mucosa (scored from 0 to 4); (c) mucosal damage(scored from 0 to 4); (d) submucosal oedema (scored from 0 to 4); (e) lesion range(scored from 0 to 4 ).

\section{Statistical analysis}

All experiments were performed at least three times. Data were reported as means \pm SD and the statistical significance was assessed by one-way analysis of variance followed by Students-Newman-Keuls tests. A value of $p \leq 0.05$ was considered to be significant. Kaplan-Meier curves were constructed to compare survival. Diferences in survival were evaluated with the Mantel-Cox test. A value of $p \leq 0.05$ was considered to be significant.

\section{Abbreviations}

CK8, keratin 8; CRC, colorectal cancer; CAC, colitis-associated colorectal cancer; AOM, azoxymethane; DSS, dextran sodium sulfate; TNF $\alpha$, tumor necrosis factor alpha; IBD, Inflammatory bowel disease; WT, wild type; TLRs, Toll-like receptor; IF, Intermediate filaments. 


\section{Authors' contributions}

Chao Liu, En-Dong Liu, Xiao-Ming Dong, YunXiao Meng, Ya-Lan Bi, Huan-Wen Wu, Yan-Chao Jin, Jing-Hui Yao, Ke Zhao, Miao Yu, Yi-Qun Zhan, Hui Chen, and Chang-Hui Ge performed the experiments. Chao Liu and Chang-Yan Li analyzed the data. Xiao-Ming Yang designed the experiments and contributed to writing the manuscript. Chang-Yan Li designed and performed experiments, analyzed the data and contributing to writing the manuscript.

\section{CONFLICTS OF INTEREST} interests.

All the authors declare no competing financial

\section{FUNDING}

This work was supported by Chinese National Natural Science Foundation Projects (31170712, 81222005); and Special Funds for Major State Basic Research of China (2014CBA02001, 2012AA020206, 2012ZX09301003-001-001, and 2013CB910800).

\section{REFERENCES}

1. Eaden JA, Abrams KR, Mayberry JF. The risk of colorectal cancer in ulcerative colitis: a meta-analysis. Gut. 2001; 48:526-35. https://doi.org/10.1136/gut.48.4.526.

2. Terzic J, Grivennikov S, Karin E, Karin M. Inflammation and colon cancer. Gastroenterology. 2010; 138:2101-14.e5. https://doi.org/10.1053/j.gastro.2010.01.058.

3. Rubin DT, Huo D, Kinnucan JA, Sedrak MS, McCullom NE, Bunnag AP, Raun-Royer EP, Cohen RD, Hanauer SB, Hart J, Turner JR. Inflammation is an independent risk factor for colonic neoplasia in patients with ulcerative colitis: a case-control study. Clin Gastroenterol Hepatol. 2013; 11:1601-8.e1-4. https://doi.org/10.1016/j. cgh.2013.06.023.

4. Lakatos PL, Lakatos L. Risk for colorectal cancer in ulcerative colitis: changes, causes and management strategies. World J Gastroenterol. 2008; 14:3937-47. https:// doi.org/10.3748/wjg.14.3937.

5. Fuchs E, Weber K. Intermediate filaments: structure, dynamics, function, and disease. Annu Rev Biochem. 1994; 63:345-82. https://doi.org/10.1146/annurev. bi.63.070194.002021.

6. Moll R, Franke WW, Schiller DL, Geiger B, Krepler R. The catalog of human cytokeratins: patterns of expression in normal epithelia, tumors and cultured cells. Cell. 1982; 31:11-24. https://doi.org/10.1016/0092-8674(82)90400-7.

7. Oshima RG, Baribault H, Caulin C. Oncogenic regulation and function of keratins 8 and 18. Cancer Metastasis Rev. 1996; 15:445-71. https://doi.org/10.1007/BF00054012.
8. Baribault H, Penner J, Iozzo RV, Wilson-Heiner M. Colorectal hyperplasia and inflammation in keratin 8-deficient FVB/N mice. Genes Dev. 1994; 8:2964-73. https://doi.org/10.1101/gad.8.24.2964.

9. Habtezion A, Toivola DM, Butcher EC, Omary MB. Keratin-8-deficient mice develop chronic spontaneous Th2 colitis amenable to antibiotic treatment. J Cell Sci. 2005; 118:1971-80. https://doi.org/10.1242/jcs.02316.

10. Toivola DM, Krishnan S, Binder HJ, Singh SK, Omary MB. Keratins modulate colonocyte electrolyte transport via protein mistargeting. J Cell Biol. 2004; 164:911-21. https:// doi.org/10.1083/jcb.200308103.

11. Owens DW, Wilson NJ, Hill AJ, Rugg EL, Porter RM, Hutcheson AM, Quinlan RA, van Heel D, Parkes M, Jewell DP, Campbell SS, Ghosh S, Satsangi J, et al. Human keratin 8 mutations that disturb filament assembly observed in inflammatory bowel disease patients. J Cell Sci. 2004; 117:1989-99. https://doi.org/10.1242/jcs.01043.

12. Polley AC, Mulholland F, Pin C, Williams EA, Bradburn DM, Mills SJ, Mathers JC, Johnson IT. Proteomic analysis reveals field-wide changes in protein expression in the morphologically normal mucosa of patients with colorectal neoplasia. Cancer Res. 2006; 66:6553-62. https://doi. org/10.1158/0008-5472.CAN-06-0534.

13. Knosel T, Emde V, Schluns K, Schlag PM, Dietel M, Petersen I. Cytokeratin profiles identify diagnostic signatures in colorectal cancer using multiplex analysis of tissue microarrays. Cell Oncol. 2006; 28:167-75.

14. Dong XM, Liu ED, Meng YX, Liu C, Bi YL, Wu HW, Jin YC, Yao JH, Tang LJ, Wang J, Li M, Zhang C, Yu M, et al. Keratin 8 limits TLR-triggered inflammatory responses through inhibiting TRAF6 polyubiquitination. Sci Rep. 2016; 6:32710. https://doi.org/10.1038/srep32710.

15. Wang L, Srinivasan S, Theiss AL, Merlin D, Sitaraman SV. Interleukin-6 induces keratin expression in intestinal epithelial cells: potential role of keratin-8 in interleukin6-induced barrier function alterations. J Biol Chem. 2007; 282:8219-27. https://doi.org/10.1074/jbc.M604068200.

16. Shen L, Turner JR. Role of epithelial cells in initiation and propagation of intestinal inflammation. Eliminating the static: tight junction dynamics exposed. Am J Physiol Gastrointest Liver Physiol. 2006; 290:G577-82. https://doi. org/10.1152/ajpgi.00439.2005.

17. Habtezion A, Toivola DM, Asghar MN, Kronmal GS, Brooks JD, Butcher EC, Omary MB. Absence of keratin 8 confers a paradoxical microflora-dependent resistance to apoptosis in the colon. Proc Natl Acad Sci USA. 2011; 108:1445-50. https://doi.org/10.1073/pnas.1010833108.

18. Omary MB, Ku NO, Strnad P, Hanada S. Toward unraveling the complexity of simple epithelial keratins in human disease. J Clin Invest. 2009; 119:1794-805. https://doi. org/10.1172/JCI37762.

19. Neufert C, Becker C, Neurath MF. An inducible mouse model of colon carcinogenesis for the analysis of sporadic and inflammation-driven tumor progression. Nat Protoc. 2007; 2:1998-2004. https://doi.org/10.1038/nprot.2007.279. 
20. Popivanova BK, Kitamura K, Wu Y, Kondo T, Kagaya T, Kaneko S, Oshima M, Fujii C, Mukaida N. Blocking TNFalpha in mice reduces colorectal carcinogenesis associated with chronic colitis. J Clin Invest. 2008; 118:560-70.

21. Frank DN, St Amand AL, Feldman RA, Boedeker EC, Harpaz N, Pace NR. Molecular-phylogenetic characterization of microbial community imbalances in human inflammatory bowel diseases. Proc Natl Acad Sci USA. 2007; 104:13780-85. https://doi.org/10.1073/ pnas.0706625104.

22. Strober W. Impact of the gut microbiome on mucosal inflammation. Trends Immunol. 2013; 34:423-30. https:// doi.org/10.1016/j.it.2013.07.001.

23. Arthur JC, Perez-Chanona E, Muhlbauer M, Tomkovich $\mathrm{S}$, Uronis JM, Fan TJ, Campbell BJ, Abujamel T, Dogan B, Rogers AB, Rhodes JM, Stintzi A, Simpson KW, et al. Intestinal inflammation targets cancer-inducing activity of the microbiota. Science. 2012; 338:120-23. https://doi. org/10.1126/science. 1224820.

24. Rakoff-Nahoum S, Paglino J, Eslami-Varzaneh F, Edberg S, Medzhitov R. Recognition of commensal microflora by toll-like receptors is required for intestinal homeostasis. Cell. 2004; 118:229-41. https://doi.org/10.1016/j. cell.2004.07.002.

25. Kitajima S, Morimoto M, Sagara E, Shimizu C, Ikeda Y. Dextran sodium sulfate-induced colitis in germ-free IQI/Jic mice. Exp Anim. 2001; 50:387-95. https://doi.org/10.1538/ expanim.50.387.

26. Lupp C, Robertson ML, Wickham ME, Sekirov I, Champion OL, Gaynor EC, Finlay BB. Host-mediated inflammation disrupts the intestinal microbiota and promotes the overgrowth of Enterobacteriaceae. Cell Host Microbe. 2007; 2:204. https://doi.org/10.1016/j.chom.2007.08.002.

27. Nagalingam NA, Kao JY, Young VB. Microbial ecology of the murine gut associated with the development of dextran sodium sulfate-induced colitis. Inflamm Bowel Dis. 2011; 17:917-26. https://doi.org/10.1002/ibd.21462.

28. Nagamine CM, Rogers AB, Fox JG, Schauer DB. Helicobacter hepaticus promotes azoxymethane-initiated colon tumorigenesis in BALB/c-IL10-deficient mice. Int J Cancer. 2008; 122:832-38. https://doi.org/10.1002/ ijc. 23175 .

29. Ramms L, Fabris G, Windoffer R, Schwarz N, Springer R, Zhou C, Lazar J, Stiefel S, Hersch N, Schnakenberg U, Magin TM, Leube RE, Merkel R, Hoffmann B. Keratins as the main component for the mechanical integrity of keratinocytes. Proc Natl Acad Sci USA. 2013; 110:1851318. https://doi.org/10.1073/pnas.1313491110.

30. Fu DJ, Thomson C, Lunny DP, Dopping-Hepenstal PJ, McGrath JA, Smith FJ, McLean WH, Pedrioli DM. Keratin 9 is required for the structural integrity and terminal differentiation of the palmoplantar epidermis. J Invest Dermatol. 2014; 134:754-63. https://doi.org/10.1038/ jid.2013.356.
31. Odaka C, Loranger A, Takizawa K, Ouellet M, Tremblay MJ, Murata S, Inoko A, Inagaki M, Marceau N. Keratin 8 is required for the maintenance of architectural structure in thymus epithelium. PLoS One. 2013; 8:e75101. https://doi. org/10.1371/journal.pone.0075101.

32. Dignass AU, Baumgart DC, Sturm A. The aetiopathogenesis of inflammatory bowel disease-immunology and repair mechanisms. Aliment Pharmacol Ther. 2004; 20:9-17. https://doi.org/10.1111/j.1365-2036.2004.02047.x.

33. Collins D, Hogan AM, Winter DC. Microbial and viral pathogens in colorectal cancer. Lancet Oncol. 2011; 12:504 12. https://doi.org/10.1016/S1470-2045(10)70186-8.

34. Wu S, Rhee KJ, Albesiano E, Rabizadeh S, Wu X, Yen HR, Huso DL, Brancati FL, Wick E, McAllister F, Housseau F, Pardoll DM, Sears CL. A human colonic commensal promotes colon tumorigenesis via activation of $\mathrm{T}$ helper type $17 \mathrm{~T}$ cell responses. Nat Med. 2009; 15:1016-22. https://doi.org/10.1038/nm.2015.

35. Erdman SE, Poutahidis T, Tomczak M, Rogers AB, Cormier K, Plank B, Horwitz BH, Fox JG. CD4+ CD25+ regulatory $\mathrm{T}$ lymphocytes inhibit microbially induced colon cancer in Rag2-deficient mice. Am J Pathol. 2003; 162:691-702. https://doi.org/10.1016/S0002-9440(10)63863-1.

36. Zhu Q, Jin Z, Wu W, Gao R, Guo B, Gao Z, Yang Y, Qin $\mathrm{H}$. Analysis of the intestinal lumen microbiota in an animal model of colorectal cancer. PLoS One. 2014; 9:e90849. https://doi.org/10.1371/journal.pone.0090849.

37. Wang T, Cai G, Qiu Y, Fei N, Zhang M, Pang X, Jia W, Cai $\mathrm{S}$, Zhao L. Structural segregation of gut microbiota between colorectal cancer patients and healthy volunteers. ISME J. 2012; 6:320-29. https://doi.org/10.1038/ismej.2011.109.

38. Belcheva A, Irrazabal T, Robertson SJ, Streutker C, Maughan H, Rubino S, Moriyama EH, Copeland JK, Kumar S, Green B, Geddes K, Pezo RC, Navarre WW, et al. Gut microbial metabolism drives transformation of MSH2deficient colon epithelial cells. Cell. 2014; 158:288-99. http://dx.doi.org/10.1016/j.cell.2014.04.051.

39. Dingemanse C, Belzer C, van Hijum SA, Gunthel M, Salvatori D, den Dunnen JT, Kuijper EJ, Devilee P, de Vos WM, van Ommen GB, Robanus-Maandag EC. Akkermansia muciniphila and Helicobacter typhlonius modulate intestinal tumor development in mice. Carcinogenesis. 2015; 36:1388-96. https://doi.org/10.1093/carcin/bgv120.

40. Castiglioni V, Vailati Facchini R, Mattiello S, Luini M, Gualdi V, Scanziani E, Recordati C. Enterohepatic Helicobacter spp. in colonic biopsies of dogs: molecular, histopathological and immunohistochemical investigations. Vet Microbiol. 2012; 159:107-14. https://doi.org/10.1016/j. vetmic.2012.03.026

41. Kim TJ, Kim ER, Chang DK, Kim YH, Baek SY, Kim K, Hong SN. Helicobacter pylori infection is an independent risk factor of early and advanced colorectal neoplasm. Helicobacter. 2017; 22:e12377. https://doi.org/10.1111/ hel.12377. 
42. Nam JH, Hong CW, Kim BC, Shin A, Ryu KH, Park BJ, Kim B, Sohn DK, Han KS, Kim J, Lee CW. Helicobacter pylori infection is an independent risk factor for colonic adenomatous neoplasms. Cancer Causes Control. 2017; 28:107-15. https://doi.org/10.1007/s10552-016-0839-x.

43. Kawahara T, Teshima S, Oka A, Sugiyama T, Kishi K, Rokutan K. Type I Helicobacter pylori lipopolysaccharide stimulates toll-like receptor 4 and activates mitogen oxidase 1 in gastric pit cells. Infect Immun. 2001; 69:4382-89. https://doi.org/10.1128/IAI.69.7.4382-4389.2001.

44. Fukata M, Chen A, Vamadevan AS, Cohen J, Breglio K, Krishnareddy S, Hsu D, Xu R, Harpaz N, Dannenberg AJ, Subbaramaiah K, Cooper HS, Itzkowitz SH, et al. Toll-like receptor- 4 promotes the development of colitis-associated colorectal tumors. Gastroenterology. 2007; 133:1869-81. https://doi.org/10.1053/j.gastro.2007.09.008.

45. Fukata M, Chen A, Klepper A, Krishnareddy S, Vamadevan AS, Thomas LS, Xu R, Inoue H, Arditi M, Dannenberg AJ, Abreu MT. Cox-2 is regulated by Toll-like receptor-4 (TLR4) signaling: Role in proliferation and apoptosis in the intestine. Gastroenterology. 2006; 131:862-77. http:// dx.doi.org/10.1053/j.gastro.2006.06.017.

46. Sanada Y, Mizushima T, Kai Y, Nishimura J, Hagiya H, Kurata H, Mizuno H, Uejima E, Ito T. Therapeutic effects of novel sphingosine-1-phosphate receptor agonist W-061 in murine DSS colitis. PLoS One. 2011; 6:e23933. https:// doi.org/10.1371/journal.pone.0023933. 